\title{
El libro de los Proverbios como fuente sapiencial: nuevos datos sobre la difusión de los romanceamientos bíblicos castellanos de origen judío*
}

\author{
Carlos N. Sainz de la Maza** \\ I. U. «Menéndez Pidal», U. C. M \\ ORCID ID: http://orcid.org/0000-0003-1273-3220
}

El estudio comparativo de las citas bíblicas incluidas en las obras literarias medievales, en especial las de tipo didáctico-moral y las de polémica religiosa, es un instrumento útil para intentar aproximarse a los procesos de difusión de las biblias romanceadas castellanas. Analizamos aquí la significativa relación existente entre los versículos del libro de los Proverbios incluidos en la obra sapiencial Palabras breves, dichos de sabios y dicho corpus bíblico.

Palabras Clave: Siglo XV, Corona de Castilla; conversos; literatura sapiencial; biblias romanceadas; uso y transmisión de versiones.

The Book of Proverbs as a Source for Wisdom Literature: New Data on the Dissemination of Castilian Romance Bibles of Jewish Origin.- The comparative study of biblical quotes included in medieval literary works, especially those belonging to a didacticmoral kind and to religious controversy, is a useful tool for approaching the processes of dissemination of Castilian Romance Bibles. In this paper I analyze the significant relation between the verses from the Book of Proverbs included in the wisdom book Palabras breves, dichos de sabios and that biblical corpus.

Keywords: Fifteenth Century; Crown of Castile; Conversos; Wisdom literature; Romance Bibles; Versions transmitted and its employment.

"Este trabajo se inscribe en el marco del Proyecto de Investigación del Plan Nacional de I+D+I «Ciencia y religión en el judaísmo de la Iberia medieval» (ref. núm. FFI201675230-P).

csmaza@ filol.ucm.es

Copyright: () 2017 CSIC. Este es un artículo de acceso abierto distribuido bajo los términos de una licencia de uso y distribución Creative Commons Attribution (CC-by) España 3.0. 
En 2008, Marta Haro daba a conocer y editaba la colección sapiencial Palabras breves, dichos de sabios ${ }^{1}$, donde incluía una serie de interesantes conjeturas sobre su formación y las intenciones de su compilador cuatrocentista. Este, que abría su selección de sententiae adaptando una parte del popularísimo Libro de los buenos proverbios, antologaba como segunda sección de su obra -sin separación explícita ni ningún otro tipo de referencia que la identificara- un interesantísimo material proverbial tomado de un romanceamiento del tratado misnaico Abot ${ }^{2}$. Poco después, Carlos Sainz de la $\mathrm{Maza}^{3}$ perfilaba la caracterización del compilador de la obrita en el comentario que acompañaba a su edición crítica de esos mismos textos rabínicos, estudiados a la luz de los otros dos testimonios castellanos conocidos de Abot: el tratado completo contenido en el manuscrito 2015 de la Biblioteca Universitaria de Salamanca ${ }^{4}$, y los fragmentos procedentes de la Guenizá de El Cairo que conserva la University Library de Cambridge 5 . De su análisis se concluía que

estos tres testimonios de Pirqué Abot en castellano antiguo remiten, a pesar de sus distintas procedencia y ámbito de difusión, a un antepasado común. Parece poco probable que este fuese un romanceamiento exento de Abot [...]. El antecesor de las versiones castellanas que nos ocupan formaría, casi con seguridad, parte de algún Siddur o libro de oraciones romanceado parecido al que Yom Tob Attías trasladó "del hebraico de verbo a verbo de antiguos exemplares" para luego imprimirlo en Ferrara en 1552 [...] Nada impide suponer, aunque no constituya tampoco una

\footnotetext{
${ }^{1}$ M. Haro Cortés. «Aristóteles, los sabios judíos y Salomón en una colección de sentencias inédita, Palabras breves: dichos de sabios», Revista de Filología Española 88 (2008) págs. 37-66.

${ }^{2}$ Sentencias 75 a 122; HARO CoRTés, «Aristóteles», págs. 60-64.

${ }^{3}$ En «Abot de los conversos ca. 1450», eHumanista/Conversos 1 (2013) págs. 86-104.

${ }^{4}$ Ocupa los fols. XXXII $v$-XLIII $r$ del códice, formado por una interesante miscelánea de textos vinculados al mundo judeoconverso castellano de mediados del siglo XV; lo edita M. LAZAR, Sēfer Tešubāh [Book on Repentance]. A Ladino compendium of Jewish law and ethics (Culver City, 1993), págs. 63-81. Sobre la formación y significado de este manuscrito, vid. también A. Alba y C. SAINZ DE LA MAZA, «Señas de identidad judías y cristianas en la cuentística medieval: algunos ejemplos hispánicos», Sefarad 72 (2012) págs. 145-190: 165-168.

${ }^{5}$ Los dio a conocer E. Gutwirth, «A Medieval Spanish Translation of Avot: Genizah Fragments», Annali dell'Istituto Orientale di Napoli 49 (1989) págs. 289-300. Para lo que sigue, vid. SAINZ DE LA MAZA, «Abot de los conversos», págs. 90-96.
} 
condición necesaria para ello, que la transmisión del texto castellano, hasta el momento de su plasmación material en los tres testimonios manuscritos conservados, se haya efectuado exclusivamente por medio de estos libros de oraciones en romance, cuya amplia circulación atestiguan las actas de los procesos inquisitoriales y, también, algún precioso ejemplar del propio siglo $\mathrm{XV}^{6}$.

A pesar de que la fuente utilizada por el compilador de Palabras breves remite al contexto de supervivencia y reconstrucción de la conciencia identitaria judía que caracteriza el segundo cuarto del siglo XV peninsular, los cambios y supresiones que aquel introducía en el texto romance original, reflejo de su palpable deseo de sofocar cualquier eco de la rebosante judeidad de Abot, permitían afirmar que el texto antologado en el manuscrito madrileño

es obra de algún converso plenamente identificado con el Cristianismo «viejo», distanciado de las posturas reivindicativas adoptadas por tantos otros miembros de su grupo social en respuesta a las variadas formas de rechazo que hubieron de sufrir a lo largo del siglo XV; un compilador probablemente deseoso de que su peculiar repertorio sapiencial fuera «asimilado por la ortodoxia cristiana» (Haro Cortés: 49). Su público lector no es, pues, judío, ni hay que buscarlo entre los conversos que, judaizantes o no, reverenciaban el legado tradicional de las Leyes mosaica y oral ${ }^{7}$.

La sección final de Palabras breves -igualmente copiada sin ningún tipo de solución de continidad en el manuscrito- es, de nuevo, una selección de una obra relacionada con la tradición sapiencial transmitida desde el Judaísmo antiguo, aunque en este caso incorporada posteriormente al canon cristiano: el libro de los Proverbios del Antiguo Testamento. El compilador de Palabras breves ha escogido para su colección una parte de Pr 25-29, una de las tres últimas secciones del libro, formada por la colección de máximas recogidas en tiempos de Ezequías, rey de Judá (ca. 715-686 a. C. $)^{8}$.

A la vista de los datos que se deducían del material procedente de Abot, parece ahora conveniente preguntarse si es posible aproximarse a

\footnotetext{
${ }^{6}$ SAinz de la MAZA, «Abot de los conversos», pág. 96.

${ }^{7}$ SAinz de la MAZA, «Abot de los conversos», pág. 95.

${ }^{8}$ La selección espiga parte de las máximas contenidas entre Pr 25:8 y Pr 29:3.
} 
la versión bíblica utilizada como fuente de esta antología parcial del libro de los Proverbios, y si la identificación de la misma y el tratamiento dado a los versículos escogidos permiten añadir algo a lo que ya sabemos sobre el proceso de composición de Palabras breves. En principio, la pertenencia de Proverbios al canon bíblico cristiano parece eliminar la necesidad de recurrir a ningún tipo de modificación desjudaizadora; no está tan claro, sin embargo, que la condición modélicamente sapiencial de la fuente elegida pueda servir, sin más, para preservarla de retoques estilísticos: en efecto, la pauta rítmica de sobria concisión, un tanto cortante, propia de una obra como el Libro de los buenos proverbios, no encuentra apenas reflejos en las formulaciones más complejas, basadas casi siempre en el juego con la bimembración de carácter contrastivo o paralelístico, de las sentencias atribuidas a Salomón en las Escrituras'. Para valorar el tratamiento dado a su fuente por el compilador de Palabras breves, identificando, a la vez, en la medida de lo posible, cuál fue el tronco genético vernáculo del que se extrajeron las citas bíblicas transcritas en el manuscrito madrileño, hemos confrontado la selección incluida en Palabras breves con la panoplia textual de las biblias romanceadas, cuya consulta en paralelo -con el añadido del texto masorético y la Vulgata latina- nos facilita desde hace pocos años la web Biblia Medieval ${ }^{10}$; panoplia que se ha ampliado, a modo de piedra de toque textual, a la Biblia de Ferrara, la versión romance más próxima, por su carácter de calco deliberado, al original hebreo ${ }^{11}$. En cuanto a las correspondientes máximas de Palabras breves, se ha revisado a fondo la transcripción de Marta Haro (que designamos como MH), cotejándola con el manuscrito Mss 5644 de la BNE, del que procede (desde ahora, $M$ ), lo que nos ha permitido subsanar algunos errores e imprecisiones -a veces, francamente sorprendentes- de aquella.

\footnotetext{
${ }^{9}$ Para una tipología detallada de estos recursos, vid. A. Alba y C. Sainz de la Maza, «Amóstrame Gan Eden: pautas formales de lo sapiencial en las biblias judeoespañolas de la Edad Media», Revista de Poética Medieval 23 (2009) págs. 41-77.

${ }^{10}$ Disponible en línea en <http://corpus.bibliamedieval.es/>.

${ }^{11}$ Las citas de esta obra las tomamos de Biblia de Ferrara, ed. M. Lazar (Madrid, 1996), que citaremos como $F$. Para citas de otras biblias romanceadas adoptamos las siglas del citado corpus Biblia Medieval, aunque actualizamos «BNM» como «BNE» y seguimos denominando «Alba» la que allí se cita como «Arragel». Designaremos la Biblia hebrea como TM y la Vulgata latina como Vg.
} 
El resultado del cotejo de los proverbios recogidos en Palabras breves con sus equivalentes de los romanceamientos medievales es más que notable, tanto en términos de filiación como del tratamiento que una parte de los pasajes seleccionados sufre a manos del compilador. Como se verá en la transcripción paralela de cada sentencia, la sección final de Palabras breves bebe de una Biblia en romance castellano que, al menos para $\mathrm{Pr}$, y con alguna excepción cercana a otros romanceamientos o independiente de todos los conservados, sigue muy de cerca la versión de ese libro contenida en la pareja de manuscritos escurialenses I.i.7 e I.i.5 (desde ahora, E7 y E5, respectivamente) y en la variante de esa misma versión representada por el códice CXXIV/1-2 de la Biblioteca Pública de Évora (Portugal; desde ahora, Ev). Su empleo en Palabras breves añade un nuevo testimonio de la difusión de esta familia de biblias, cuya matriz podría haber sido traducida al castellano durante el último decenio del siglo $\mathrm{XIV}^{12}$, e ilustra igualmente la utilización práctica a que, como libros de consulta de aplicación más amplia que las de su uso meramente moral o devocional, podrían haber estado destinadas estas obras de tan amplia circulación durante los últimos siglos medievales.

Frente a E7/E5 [Ev], $M$ (o, más bien, su fuente bíblica, si dejamos de lado las esporádicas intervenciones del compilador ${ }^{13}$ ) presenta algunos rasgos propios. Por ejemplo, no siempre comparte la querencia de aquellas por la originalidad de la expresión ${ }^{14}$ (vid. las sentencias núms. 13/Pr 26:5, 17/Pr 28:5[a] o 27/Pr 28:24, infra). Otras veces busca su propia originalidad. Así, en bastantes casos, la selección léxica revela una preocupación estilística que afina las lecturas transmitidas por los demás

\footnotetext{
${ }^{12}$ E7 se copia entre 1400-1430; E5, donde se contiene Pr, entre 1420-1445. Ev, copiada en 1429, parece seguir E5; pero vid. lo que decimos infra. Además de los enlaces contenidos en Biblia Medieval, vid. el minucioso estudio de F. J. Pueyo Mena y A. Enrique-Arias, «Los romanceamientos castellanos de la Biblia hebrea compuestos en la Edad Media: manuscritos y traducciones», Sefarad 73 (2013) págs. 165-224: 167-168 y 207-210.

${ }^{13}$ Este es responsable, tal vez, y como ya ocurría en el romanceamiento de Pirqué Abot antologado en el mismo Palabras breves, del uso de «Dios» frente a «Señor» en la sentencia núm. 28, Pr 28:25 (indicación abreviada en lo sucesivo como 'núm. de sentencia/Pr capítulo:versículo').

${ }^{14}$ F. J. Pueyo Mena y A. Enrique-Arias ven en esta rama de las traducciones bíblicas el producto de lo que denominan una «traducción interpretativa», que comentan en «Los romanceamientos», págs. 207-210.
} 
romanceamientos (vid., por ej., núm. 2/Pr 25:11), la cual se traduce casi siempre en términos de preferencia por una mayor sencillez expresiva (vid. núms. 8/Pr 25:19; 19/Pr 28:6; 21/Pr 28:9, y 30/Pr 28:28) ${ }^{15}$. Es, además, sistemático el recurso a «loco» en vez de «nescio» (vid. núms. 12/Pr 26:4; y 13/Pr 26:5; 14/Pr 26:12, y 28/Pr 28:26) o «confiança» en vez de «fiuza» (vid. núms. 8/Pr 25:19 y 14/Pr 26:12).

Frente a las numerosísimas coincidencias, hay lecturas que muestran la independencia de $M$ con respecto a E7/E5 (vid. núms. 22/Pr 28:14 o 29/Pr 28:27) y a Ev (vid. núms. 11/Pr 25:24 o 23/Pr 28:19). Esas lecturas propias apuntan, en algún caso, hacia otras biblias romanceadas: la sentencia núm. 12/Pr 26:4, por ej., se acerca más a E3 y Alba. En otras ocasiones, $M$ lee de modo independiente, como muestran las sentencias núms. 15/Pr 28:3; 17/Pr 28:5[a]; 25/Pr 28:22; 28/Pr 28:25-26; 29/ Pr 28:27, y 30/Pr 28:28.

El conjunto, relativamente amplio, de lecturas en las que $M$ diverge de E7/E5 [Ev], o de una de estas últimas, permite aventurar algunas conclusiones de interés para la historia de las traducciones bíblicas medievales al castellano. Como se sugiere en los breves apuntes que siguen a la presentación paralela de las distintas versiones del texto de cada proverbio, tanto los textos antologados en $M$ como los correspondientes de E7/E5 y Ev parecen remitir a un antecesor común, que llamaremos $\beta$, a partir del cual tanto estas últimas como la biblia aprovechada por nuestro compilador habrían adquirido su fisionomía definitiva ${ }^{16}$, de la que hay que descontar, en $M$, los cambios debidos al compliador de Palabras breves. El conjunto permite avanzar en el conocimiento de la gestación gradual de esa «traducción interpretativa» representada hasta hoy por E7/E5 [Ev], a la que se suma, con sus particularidades, $M$ : su base estaría, precisamente, en $\beta$, que, a su vez, enlazaría con la traducción hoy representada por el códice $\mathrm{E} 3{ }^{17}$. Tal enlace no se habría producido mediante una transmisión

\footnotetext{
${ }^{15}$ En algún caso aislado, $M$ invierte esta tendencia; vid. núm. 33/Pr 29:2[b].

${ }^{16}$ Es probable que E7/E5 y Ev tengan, a su vez, un antepasado común $\gamma$. Las diferencias de $M$ con E7/E5 y Ev permiten sugerir que -al menos en lo relativo a Pr- esta última no es mera copia de la escurialense, como hasta ahora se había supuesto; $c f$., por ej., las sentencias núms. 10/Pr 25:21-22 y 15/Pr 28:3.

${ }^{17}$ Pueyo Mena y Enrique-Arias, «Los romanceamientos», pág. 168, recogiendo y ampliando las advertencias ya formuladas por Margherita Morreale (en «El códice de los
} 
textual directa, que los testimonios presentados más abajo desmienten, sino por la muy probable utilización de un ejemplar de la traducción E3 como texto de referencia y apoyo por parte del romanceador de $\beta$.

En otro orden de cosas, y como ya sucedía en las anteriores secciones de la compilación, su autor no se ha limitado a transcribir de corrido el material que selecciona. Aunque de modo irregular, el compilador modifica el texto de su fuente bíblica con arreglo a ciertos criterios bien definidos:

1. Elisión parcial de versículos:

a. Supresión de parte del proverbio: en 31, corta el proverbio para quedarse sólo con su primera mitad: Pr 29:1[a]. Hace lo mismo en 34 con 29:3[a].

b. División de un proverbio en dos sentencias consecutivas: en 17 y 18, lo hace con Pr 28:25: en 17 deja sólo la primera parte del proverbio (Pr 28:5[a]); en 18, la segunda (Pr 28:5[b]). Hace lo mismo en 32 y 33 con $\operatorname{Pr} 29: 2^{18}$.

2. Encadenamiento de versículos ${ }^{19}$. Se omite, de modo aparentemente no fortuito, el calderón esquemático que abre la sentencia o la marca de cierre de la misma:

a. En 10 se enlazan, sin recortes, $\operatorname{Pr} 25: 21-22$. En 28 se encadenan dos versículos de sentido similar, Pr 28:25-26.

Profetas en latín y castellano que se conserva en la Biblioteca de la Academia de la Historia (87)», BRAH 150 [1962] págs. 133-149) a comienzos de la década de1960, subrayan la diferencia entre la unidad codicológica que es el manuscrito y la unidad textual que constituiría la traducción bíblica que este recoge de diversos modos: el texto conservado en el primero, aun recogiendo, como en E3, el conjunto de una única traducción bíblica, presenta siempre un cierto porcentaje de variación con respecto a la misma. Caracterizan esa rama de las traducciones bíblicas castellanas como «un texto de origen judío, muy apegado a la tradición bíblica comunitaria, que hubo de tener una cierta difusión entre lectores cristianos durante la Edad Media» (pág. 205).

${ }^{18}$ Los dichos tomados del Libro de los buenos proverbios que abren Palabras breves ofrecen con preferencia sentencias no paralelísticas; en algún caso se suceden dos sentencias complementarias, creando un efecto similar al que aquí produce la división de los proverbios bíblicos, como se ve, por ej., en las sentencias 27 («El que pensó, estorçió») y 28 («El que preguntó, aprendió»); vid. Haro, «Aristóteles», págs. 44 y 54.

${ }^{19}$ En la sección inicial de Palabras breves hay también algún ejemplo de encadenamiento de sentencias; vid. HaRO, «Aristóteles», pág. 43. 
b. En 1, se recortan varios proverbios para formar una sentencia facticia con $\operatorname{Pr} 25: 8[\mathrm{~b}]-9[\mathrm{~b}]-10^{20}$.

c. En 9, se traspone el tercer miembro de Pr 25:20 al segundo lugar de la sentencia. Puede obedecer al deseo de reformular el proverbio en la forma, clásica en el género, de contraposición entre una actividad humana concreta y una circunstancia o situación más general.

3. Omisión de versículos aislados o de grupos de versículos. A veces sirve para dar continuidad conceptual a la selección (Pr 26:6-11 entre núms. 13-14; Pr 28:21 entre núms. 24 y 25; Pr 28:8 entre núms. 20 y 21; parte de Pr 28:10-13 entre núms. 21 y 22); otras, se diría que revela una tendencia a prescindir de determinados tipos de proverbio: por contenido, los atmosféri$\cos (\operatorname{Pr} 25: 13-14$ entre núms. 3 y 4; $\operatorname{Pr}$ 25:23 entre núms. 10 y 11 ; etc. ${ }^{21}$ ) o alguno relacionado con la naturaleza (animales, en Pr 28:15, tras núm. $22^{22}$ ); por disposición rítmico-sintáctica, al principio parece rechazar los bimembres, típicos de Pr y de toda la tradición hebrea ${ }^{23}$, luego los reincorpora (núm. 16/Pr 28:4; y luego, núm. 20/Pr 28:27, núm. 22 y ss., passim).

La antología de Pr 25-29 que forma la parte final de Palabras breves: dichos de sabios se abre con las cuatro últimas máximas del f. lxxxvr (83r) de $M$. La presentamos y comentamos, tal y como la dispone el compilador de la obra ${ }^{24}$ y en paralelo con los textos bíblicos romances que constituyen la referencia más cercana a cada versículo, referencias que, como ya se ha indicado, ligan casi siempre las sentencias de Palabras

\footnotetext{
${ }^{20}$ Vid. infra el comentario correspondiente sobre el posible origen de este conglomerado.

${ }^{21} C f$., por ej., Pr 25:14 según E7/E5: «Nublos e vientos, e rocíos non aviendo, tal es el varón alabancioso con la dádiva falsa».

${ }^{22}$ Cf. E7/E5: «León bravo e oso arremetedor: así es cuando tiene poderío el malo contra el pueblo menesteroso».

${ }^{23}$ Vid. Alba y SAINZ DE LA MAZA, «Amóstrame Gan Eden», págs. 54 y 57-61.

${ }^{24}$ Las enmiendas al texto de $\mathrm{MH}$ se sustentan en una nueva y atenta lectura del manuscrito conservado en la BNE; debo a la generosidad y sabiduría paleográfica de mi compañera de la UCM Paloma Cuenca (Fac. de Geografía e Historia, Depto. de Ciencias y técnicas historiográficas) la resolución de algún caso en que las grafías del códice planteaban dudas o dificultades de cierto calado.
} 
breves a la familia de biblias representada por la pareja de códices escurialenses E7/E5 y por Ev. Añadimos el texto de E3 para calibrar, sobre todo, el valor de los pasajes de $M$ con respecto al romanceamiento matriz $\beta$, así como el hebreo de TM y los versículos-calco correspondientes de $F$ para contrastar el grado de literalidad del conjunto de la versión. En cuanto a la disposición de los textos de Palabras breves, los presentamos respetando los signos gráficos que, en el manuscrito, separan e identifican cada una de las que podríamos llamar «unidades sapienciales». Así, incluimos los calderones que, en forma de breves trazos estilizados, pero muy visibles, abren las sententiae (alterando con ello, a veces, la distribución original de los proverbios bíblicos). Transcribimos igualmente las marcas de cierre de las mismas, calcándolas como « $(\cdot\rangle^{25}$. Los breves comentarios que siguen a las distintas versiones de cada versículo llaman la atención sobre las particularidades estilísticas de $M$ y se cierran con la enumeración de los cambios experimentados en el proceso de constitución de $\beta$-con E3 como modelo auxiliar, según se ha apuntado supra- y de sus descendientes E7/E5 [Ev] y la fuente de Palabras breves. Dichos procesos se marcan con los signos « $\rightarrow »-$ paso de una biblia a otra $-\mathrm{y}$ « >» -cambio en un término o expresión concretos-.

\footnotetext{
${ }^{25}$ Los criterios generales de transcripción, válidos también para las citas sacadas de las biblias romanceadas medievales y $F$, son los siguientes: separación, acentuación y puntuación de palabras según el uso actual; «c» ante -e/-i y «ç» ante -a/-o/-u; «cua/-o» para $q u a /-o$; «m» en vez de «mm»; «ñn en vez de «nn»; distribución actual de la grafía de $\mathrm{i} / \mathrm{y} / \mathrm{j} \mathrm{y} \mathrm{u/v}$; se mantienen los trueques esporádicos de líquidas; a diferencia de $\mathrm{MH}$, se desarrollan como «np», «nb», las abreviaturas de nasal, que aparecen así en algunos casos no abreviados en el texto ( $v i d$. núm. 10/Pr 25:21, para $n b$, y núm. 24/Pr 28:20, para $n p$ ); se transcribe como «e» el signo tironiano ( $y \mathrm{MH}$ ); y como «non» el adverbio de negación (no $\mathrm{MH}$, obviando el trazo de abreviatura sobre la palabra).
} 


\section{BNE, Mss 5644, f. lxxxvr (83r):}

M om. Pr 25:1-7 26 .

1. (MH 123) Pr 25:8-10; funde al comienzo 25:8-9.

I[final de 25:8] Si te echare en vergüença tu conpañero, [final de 25:9] la poridad de otrie non le descubras ${ }^{27},[25: 10]$ por que non te eche en vergüença otra e la tu fama non sea buelta ${ }^{28}$. ( • (

E7/E5 [Ev]: [25:8] \{Non salgas al ruido apresuradamente porque non sabes qué se fará [Ev: qué será] a la fin dél\} si te envergüença [Ev: envergonçará] tu conpañero. [25:9] \{El tu roido serié [Ev: sería] por el roido de tu conpañero; $\}$ secreto $^{29}$ [Ev: e secreto] de otro non descubras, [25:10] por que non te eche en vergüença el que lo oyere e la tu fama non se enbuelva.

E3: [25:8] \{Non salgas al roido aína; mira qué fará en su fin\} cuando te avergonçaren a ti tu amigo. [25:9] \{Por tu juizio o por juizio de tu amigo\} poridad de otro non descubras, [25:10] por que non te repudie el que te oyere, e tu fama non tornará.

$F:$ [25.8] \{No salgas a baraja aína, porque no fagas en su fin, \} en que avergüence a ti tu compañero. [25:9] \{Tu baraja, baraja con tu compañero, $\}$ y secreto de otro no descubras. [25.10] Porque no te arrepudie oyén, y tu infamia no se tornará.

\footnotetext{
${ }^{26}$ Dejando aparte Pr 25:1, que funciona como epígrafe («Tanbién aquestos son Proverbios de Salamón que trasladaron las personas de Ezechías, rey de Judá»; E7/E5), Pr 25:2-7 se centran en el valor que la sabiduría aporta a la autoridad de la figura regia y a su capacidad de distinguir entre los hombres buenos y malos; buena parte son de estructura paralelística y tanto Pr 25:4-5 como Pr 25:6-7 forman dípticos, desplegando su sentido en una doble sentencia, como los casi inmediatos Pr 25:9-10, incorporados a $M$ del modo que a continuación se verá.

${ }^{27}$ MH puntúa Si [...] tu compañero la poridad de otrie, no [...]. La frase resultante carece de sentido y choca con la pertenencia de cada uno de sus miembros a un proverbio distinto.

${ }^{28}$ Para el sentido original de los versículos, $c f$. la traducción crítica de F. CANTERA BuRGOS y M. Iglesias Rodríguez (Sagrada Biblia, versión crítica sobre los textos hebreo, arameo y griego [2a ed., Madrid: La Editorial Católica, 1979]; en adelante, CANT-IGL): «[25:8] No salgas a pleitear apresuradamente, pues ¿qué harás al final, cuando te haya confundido tu prójimo? [25:9] Debate tu querella con tu prójimo, pero el secreto de otro no descubras, [25:10] no sea que te vitupere quien lo oiga, y tu difamación no tenga enmienda».

${ }^{29}$ secreto: E7/E5 le antepone un calderón, como si comenzara un versículo distinto.
} 


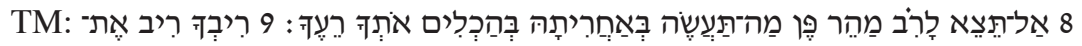

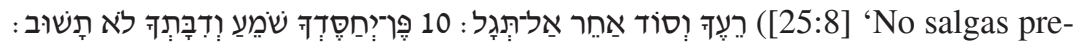
cipitadamente a la disputa, pues ¿qué harás al final, cuando te avergüence tu prójimo? [25:9] 'Debate tu querella con tu prójimo, pero el secreto de otro no descubras, [25:10] no sea que te vitupere quien lo oiga y tu infamia no tenga remedio' [lit. 'y tu fama no vuelva']).

La formación del llamativo pastiche con el que el compilador de Palabras breves abre su selección de Pr no resulta fácil de explicar. No puede provenir de la biblia usada como fuente porque, en general, el carácter sagrado del texto obliga a un cuidado en la copia que evita este tipo de mutilaciones y remiendos. Por otra parte, aunque pudiera al menos admitirse un despiste del compilador que se tradujera en un error de copia por salto entre el «compañero» de Pr 25:8 y el de Pr 25:9 (en ambos casos TM רֵעך / re 'eja 'prójimo'), la secuencia resultante Pr 25:8[2]-Pr 25:9 carecería de sentido. Sólo cabe admitir que el anónimo antólogo converso creó deliberadamente esta larga sententia facticia con el propósito de enlazar con la sección de Palabras breves sacada del coetáneo Abot castellano que antecede a los textos de Pr. Podría conjeturarse un intento inicial, luego abandonado, de enfocar estos como fuente de sentencias complejas del estilo de las tomadas de Abot; parece, sin embargo, más probable que el compilador haya buscado únicamente crear un efecto de continuidad tras el cambio de fuente sapiencial. Ese efecto estaría justificado si recordamos la última sentencia sacada de Abot, donde el amigo, la saña y el repudio en la deshonra están también presentes ${ }^{30}$. Así se explicaría también la aparentemente injustificable sustitución de «el que lo oyere» -presente, en distintas formas, en todos los romanceamientos de Pr 25:10- por ese «otra», que, además de establecer un paralelismo con el «otrie» previo de $\operatorname{Pr} 25: 9$ [2], remite a la «vergüença» que puede volver a cernirse sobre el imprudente destinatario de tan estupendo y enrevesado consejo.

\footnotetext{
${ }^{30}$ Non ruegues a tu amigo en la ora de su saña, nin lo conortes en la ora que su muerte está delant' d'él tendido, nin le demandes alguna cosa en la ora de su boto, nin fagas mucho por lo ver en el tienpo de su desonra ( • ( (Pirqué Abot IV.18; M, fol. lxxxvr [83r], MH sentencia 122); vid. SAINZ DE LA MAZA, «Abot de los conversos», pág. 102. Recuérdese que las «secciones» de Palabras breves son virtuales, no hay epígrafes o marcas de separación que las identifiquen.
} 
Por otra parte, y a pesar de las deturpaciones, puede reconocerse ya en estos versículos la pauta de filiación textual propuesta para $M$ :

[Pr 25:8(b)] E3 $\rightarrow \beta$ : «cuando»> «si», «avergonçaren»> «envergüença», «a ti» om., «amigo»> «conpañero».

$\beta \rightarrow$ E7/E5 no cambia; $\beta \rightarrow$ Ev: «envergüença» > «envergonçará».- $\beta$

$\rightarrow M$ : «envergüença» > «echare en vergüença»; el cambio puede también formar parte de los retoques del compilador, que habría buscado enlazar con el «eche en vergüença» de Pr 25:10 para dar mayor trabazón a su particular criatura sapiencial.

$[\operatorname{Pr} 25: 9(2)] \mathrm{E} 3 \rightarrow \beta$ no cambia.

$\beta \rightarrow$ E7/E5 [Ev]: «poridad»> «secreto»; $\beta \rightarrow$ Ev: «e»add. $\beta \rightarrow M$ : «otro»> «otrie», «le» add.

$[\operatorname{Pr} 25: 10] \mathrm{E} 3 \rightarrow \beta$ : «repudie» > «eche en vergüença», «la» add., «tornará» $>\ll$ se enbuelva» ${ }^{31}$.

$\beta \rightarrow$ E7/E5 [Ev]: «te» > «lo».- $\beta \rightarrow M$ : «se enbuelva» > «sea buelta». Para «otra», vid. lo dicho supra.

\section{2. (MH 124) Pr 25:11}

M: IIMançanas ${ }^{33}$ de oro guarnidas de plata es la palabra dicha en su lugar. $(\cdot(\cdot$

E7/E5 [Ev]: Mançanas de oro cubiertas de plata, la palabra dicha en su lugar.

E3: Mançanas de oro en pinturas de plata es razón fablada por sus asentamientos.

F: Mançanas de oro con pinturas de plata, palabra fablada sobre sus modos.

TM: Manzana de oro con guirnaldas [lit. 'filigranas, adornos'] de plata (es) una palabra dicha en su lugar' [lit., 'de forma conveniente, oportunamente']).

$M$, como E3 o Alba, conserva la cópula para ajustar el texto al estándar romance; reiterará el añadido en otras ocasiones. La selección

\footnotetext{
${ }^{31}$ Podría cambiarse igualmente al «sea buelta» que conserva $M$ o alguna forma del tipo «se enbolverá».

${ }^{32} \mathrm{MH}, \mathrm{n} .: 25,12$.

${ }^{33}$ mançanas $\mathrm{M}$ : manzanas $\mathrm{MH}$.
} 
léxica de «guarnidas» es, en este caso, más expresiva y se ajusta mejor al original que el genérico «cubiertas» de E7/E5 [Ev].

$\mathrm{E} 3 \rightarrow \beta$ : «en pinturas» > «cubiertas», «razón [...] asentamientos» > «la palabra [...] lugar».

$\beta \rightarrow$ E7/E5 «es» om. $-\beta \rightarrow M:$ «cubiertas» > «guarnidas».

\section{3. (MH 125) Pr 25:12.}

IIArgolla de oro e devisa preciada es el castigo de $l^{34}$ sabio a la oreja que lo escucha. $(\cdot(\cdot) \cdot$

E7/E5 [Ev]: Argolla de oro e devisa preciosa [Ev -sc-] es el castigo del sabio sobre la oreja que lo [Ev del que le] oye.

E3: Como argolla de oro e argolla de corona es cuando razona el sabidor sobre oreja que lo oye.

$F$ : Añazme de oro y collar de oro, reprehendién sabio sobre oreja oyén.

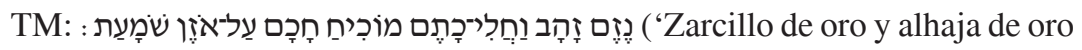
fino, un amonestador sabio a oreja atenta').

Ninguna biblia romanceada usa «escucha»; tampoco se emplea en el resto de Palabras breves, que prefiere «oír».

E3 $\rightarrow \beta$ : «Como» om., «argolla de corona» > «devisa preciosa», «cuando razona el sabidor» > «el castigo del sabio», «la» add.

$\beta \rightarrow$ E7/E5 no cambia. $-\beta \rightarrow$ Ev: «que lo» $>$ «del que le». $-\beta \rightarrow M$ : «preciosa» $>$ «preciada», «oye» $>$ «escucha».

M om. Pr 25:13-14. En ambos, las imágenes atmosféricas ${ }^{35}$ se usan como términos de comparación con lo humano.

\section{4. (MH 126) Pr 25:15.}

ICon el alongamiento de la ira se vence grand príncep ${ }^{36}$, e la lengua blanda quiebra el hueso. $(\cdot(\cdot /$ [Fol. $83 v(\mathrm{LXXXVv)}]$

E7/E5 [Ev]: Con el alongamiento de la saña entorpa el merino. La lengua blanda quebranta los huesos [Ev el hueso].

\footnotetext{
${ }^{34}$ del M: de MH.

${ }^{35} C f$. E7/E5: «la frior de la nieve», «nublos, vientos y rocíos», respectivamente.

${ }^{36}$ príncep $M$ : príncipe $\mathrm{MH}$.
} 
E3: Con pac[i]encia de saña se falaga el señor, e la lengua blanda quebranta el hueso.

$F$ : En alongamiento de furores es sombaído señor, y lengua tierna quebranta huesso.

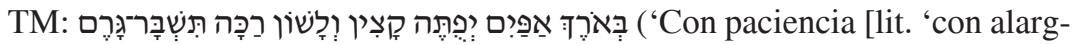
amiento de nariz (respiración)', i. e., 'con alejamiento de la ira'] se convence a un gobernante ['capitán, caudillo'] y la lengua blanda quebranta el hueso').

\&. «Se vence» es opción más moderna -y clara- que el arcaico «entorpa» ${ }^{37}$ de E7/E5, y más cercana por su sentido a TM. $M$ se distancia aquí de $\mathrm{E} 7 / \mathrm{E} 5[\mathrm{Ev}] \mathrm{y}$, en su preferencia por «príncipe» frente al más especializado «merino», queda más cerca de Alba y E4[BNE] (deudoras del «princeps» de Vg). Ninguna biblia romanceada usa «ira»; E7/E5[Ev] y E3 prefieren «saña» y el resto coinciden con Vg en limitarse al uso de «paciencia». Lo mismo para «quiebra»; todas optan por «quebranta» ${ }^{38}$.

Conjeturamos que el término «señor» empleado en E3 revela un posible punto de divergencia entre el códice conservado y la traducción original de la que éste deriva, que leería «merino», palabra que -con esta única excepción de Pr 25:15- se usa sistemáticamente, tanto en E3 como en E7/E5, como traducción exclusiva de TM קָצִין / caṣín frente a las otras voces («mayoral», «príncipe», etc.) por las que optan los demás romanceamientos $^{39}$. Así,

\footnotetext{
${ }^{37}$ El CORDE (= Real Academia Española, CORDE. Corpus diacrónico del español, accesible en http://www.rae.es da algunos ejemplos de «entorpar»-ausente en el Diccionario crítico etimológico castellano e hispánico de Joan Corominas y José Antonio Pascual ([2 ${ }^{\mathrm{a}}$ reimpr., Madrid: Gredos, 1980-1991. 6 vols.]; en adelante, Coro-Pasc)- del S. XIII, dos de ellos de Poridat de poridades y el Libro de los buenos proverbios; desde $c a$. 1370, se usa ya «entorpecer». Es vocablo escaso en los romanceamientos y casi exclusivo de E7/E5; vid. Is 19:11, Jr 10:14, 20:7 y 51:17 -en los que la sigue E4-, y -con Ev- nuestro Pr 25:15. Un caso aislado en Alba, Le 11:43, posee un sentido diverso.

${ }^{38}$ Tanto «ira» como «quiebra» están ausentes también del resto de Palabras breves.

${ }^{39}$ El muy antiguo «merino», que el CORDE registra en documentos y fueros redactados en romance desde 1129, es compartido de este modo por E3 y E7/E5 -y, en su caso, Ev- en Jos 10:24, Jc 11:6, 11:11, Is 1:10, 3:6, 3:7, 22:3 y Pr 6:7, con alguna coincidencia esporádica con E4, Aj, RAH 87 y Alba; difieren solo en Mi 3:1 y 3:9, donde E3 utiliza «mayorales», y en Dn 11:18, donde E7/E5 transmite un erróneo «un poco». En los demás casos en los que los romanceamientos emplean «merino», traducen otros términos de TM,
} 
E3 $\rightarrow \beta$ : «paciencia» > «alongamiento», tal vez ya «se falaga» > «entorpa».

$\beta \rightarrow$ E7/E5: «el hueso» > «los huesos». $\beta \rightarrow$ Ev no cambia. $-\beta \rightarrow M$ : «saña» $>$ «ira», «merino» $>$ «grand príncep», «quebranta» $>$ «quiebra».

\section{5. (MH 127) Pr 25:16.}

IICuando la miel fallares come lo que te cunple porque si te fartares avrás que gormar. $(\cdot(\cdot$

E7/E5 [Ev]: De que miel fallares come lo que te bastare [Ev: abastare], porque si te fartares avello has [Ev: averlo as] de gormar.

E3: Miel fallaste; come lo que te abastare, por que non te fartes dello e lo rindes.

$F$ : Miel fallaste; come tu abasto, porque no te hartes dél y lo gomites.

TM: : ¿'Has hallado miel? Come lo justo para ti, no sea que te harte y la vomites').

\& Ningún romanceamiento usa «cunple» -rarísimo con esta acepción en el corpus bíblico conservado ${ }^{40}$-, y sólo E7/E5 «gormar», que era palabra de reciente incorporación al castellano a comienzos del siglo $\mathrm{XV}^{41}$.

E3 $\rightarrow \beta$ : cambia el tipo de oración, «rendir» > «gormar».

$\beta \rightarrow$ E7/E5: «abastar» > «bastar».- Ev no cambia.- $M$ : «abastar» > «cunplir».

\section{6. (MH 128) Pr 25:17.}

IDevieda el tu pie de la casa de tu amigo, porque se enojará de ti e aborrecerte ha.

E7/E5 [Ev]: Alexa el tu pie de la casa de tu conpañero, porque se enojará de ti e aborrirte ha.

E3: Vazía tu pie de casa de tu amigo, por que non se farte de ti e te aborrezca.

que, sin excepción, E3 -menos en Dn 3:2, 3:3- y E7/E5 vierten con otras palabras, como puede comprobarse haciendo la correspondiente búsqueda en Biblia Medieval.

${ }^{40}$ Aparece en E7/E5 en Éx 16:16, Dt 1:6 y Ab 1:5 (éste, también en E4).

${ }^{41}$ En el CORDE se documenta por vez primera ca. 1400, en la Crónica de Pedro I de P. López de Ayala: «un ave negra [...] todo el oro del mundo encerrará en su estómago e después gormarlo ha». 
$F$ : Vieda tu pie de casa de tu compañero, porque no se harte de ti y te aborresca.

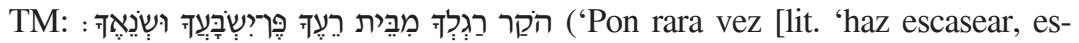
catima'] tu pie en casa de tu prójimo, no sea que se sacie de ti y te aborrezca').

Sólo $F$ usa «vieda», más cercano al «devieda» de $M$ que los más matizados «alexa», «quita» o «escusa» de las biblias castellanas medievales. Y sólo E3 vierte TM רֵֶ / re 'eja ('prójimo', 'compañero') como «amigo» ${ }^{42}$.

E3 $\rightarrow \beta$ : «vazía» > «devieda» (o, tal vez, «vieda» $)^{43}$, «non» om., «fartarse» subj. > «enojar» fut., subj. > fut. en «aborrecer».

$\beta \rightarrow$ E7/E5 [Ev]: «devieda» (o «vieda») > «alexa», «amigo» > «conpañero», «aborrecer» $>$ «aborrir». $-\beta \rightarrow M$ no cambia (o «vieda» $>\ll$ devieda»).

\section{7. (MH 129) Pr 25:18.}

ILança e espada e saeta aguda es el varón que responde contra su conpañero testimonio falso. $(\cdot(\cdot$

E7/E5 [Ev]: Lança e espada e saeta aguda es el varón que testimonia contra su conpañero testimonio falso.

E3: Facha e espada e saeta aguda es el omne que testimonia contra su amigo testigo falso.

F: Picón, y espada, y saeta aguda, varón atestiguán en su compañero testigo de falsedad.

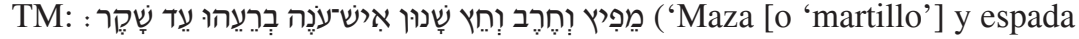
y aguda saeta es el varón que depone [lit. 'responde'] contra su compañero testimonio falso').

\footnotetext{
${ }^{42}$ El uso de «amigo» parece reflejar la glosa de Raší, cuya influencia -como la de otros glosadores judíos medievales-sobre la selección léxica de las biblias romanceadas merecería un detallado estudio en otro lugar; vid. The Complete Tanach with Rashi's Commentary, texto hebreo y trad. de R. A. J. RosenBERG, accesible en http://www.chabad.org/library/ bible_cdo/aid/16396\#showrashi=true,; señalamos infra otras posibles coincidencias.

${ }^{43}$ Existe también la posibilidad de considerar vazía -que, con el significado de 'separar, apartar', sólo aparece en E3 en Dt 19:15- como el resultado, conservado en el ms. E3, de la transmisión errónea de un viedaldevieda -más probablemente este último, usado con frecuencia en $\operatorname{Pr}$ (e incluso como «devieda tu pie» en 1:15) - ya presente en su biblia matriz.
} 
La traducción de TM מִפריץ / mefis es buen ejemplo de la variedad de soluciones ofrecida por las biblias castellanas de la época y de la dificultad que conlleva el proceso de selección léxica. La que más se acerca a TM es $F$, cuyo «picón» designa una maza-martillo, un martillo de guerra con un extremo en punta como el que, por ejemplo, enarbola el caballero que carga desde la derecha en la tabla de Paolo Uccello Niccolò da Tolentino dirigiendo a las tropas florentinas (ca. 1438-1440) $)^{44}$; la «lança» de E7/E5 y la «quasi lança» de Alba parecen inspirarse en el «jaculum» ('dardo') de Vg.

Ningún romanceamiento emplea «responde»-prefieren «testimonia», más técnico; y Alba, «dize» (cf. Vg «loquitur»)-, que refleja el gusto de $M$ por la simplicidad expresiva.

E3 $\rightarrow \beta$ : «facha» > «lança», «omne» > «varón», «amigo» > «conpañero», «testigo» > «testimonio».

$\beta \rightarrow$ E7/E5 [Ev] no cambia. $-\beta \rightarrow M:$ «testimonia» $\rightarrow$ «responde».

\section{8. (MH 130) Pr 25:19.}

IISegund la dentera a los dientes e la tronpeçadura ${ }^{45}$ al pie, así es la confiança del malo en día de tribulación $<\left(\cdot>^{46}\right.$.

E7/E5 [Ev]: Como el diente malo e el pie tronpeçador, así es la fuizia [Ev fiuzia] del aborresçedor en día de tribulación.

E3: Como diente quebrado e pie descoyuntado es tener fuzia en el falso en el día de la angustia.

$F$ : (Como) diente quebrantado y pie resvalado, (assí) confiança de falsario en día de angustia.

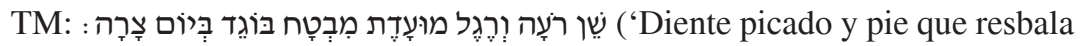
[lit. 'tropieza'] es confiar en el pérfido cuando llega el peligro' [lit. 'en día de angustia']).

\footnotetext{
${ }^{44}$ Es la primera de la serie de tres -prácticamente contemporánea de $M$ y de las biblias castellanas conservadas- que consagró el pintor a la victoria florentina de San Romano sobre los sieneses; se conserva en la National Gallery de Londres; vid. http://www. nationalgallery.org.uk/paintings/paolo-uccello-the-battle-of-san-romano.

${ }^{45}$ tronpeçadura $M$ : tropeçadura $\mathrm{MH}$.

${ }^{46}(\cdot:$ M om. La sentencia llega justo hasta el borde de la caja de escritura. 
Ni las biblias castellanas ni Vg usan la perífrasis con que $M$ evita el literalismo de «diente/pie + [adjetivo]»; nuestro texto se muestra aquí más audaz y libre que E7/E5, que se limitan a prescindir del «quebrado» con que E3 calcaba la glosa de Raší. Como es habitual en $M$, se opta por «confiança» (de uso regular en esta sección de Palabras breves) frente a «fiuzia», que usaba ya E3 («fuzia»). La sustitución de «aborrescedor» por «malo», que no usa ningún otro romanceamiento, va en ese mismo sentido modernizador, de búsqueda de un léxico simple -que, además, en este caso, aligera el texto de ecos de derivación judeo-romance ${ }^{47}$.

E3 $\rightarrow \beta$ : «quebrado» > «malo», «descoyuntado»> «tronpeçador», «tener»om., «así» add., «falso»> «aborrescedor», «angustia»> «tribulación».

$\beta \rightarrow$ E7/E5 no cambia.- $\beta \rightarrow M$ : «fiuzia» > «confiança», «aborrescedor» $>$ «malo», además de la citada perífrasis.

\section{9. (MH 131) Pr 25:20.}

IEl que enpeña la ropa en día de frío e el que canta con coraçón triste con estrumentes $^{48}$ es así como vinagre sobre greda. $(\cdot(\cdot$

E7/E5 [Ev]: El que enpeña ${ }^{49}$ su [Ev la] ropa en día de frío es así como el vinagre sobre la greda e el cantar con estrumente $<\mathrm{S}>^{50}$ [Ev sobre estrumentes] sobre coraçón triste.

E3: El que se tira la ropa en el día del frío, vinagre con greda, $<\mathrm{e}>^{51}$ el que canta cantares sobre mal coraçón.

\footnotetext{
${ }^{47}$ En las biblias romanceadas de origen judío es frecuente el uso de «aborrescedor»; el CORDE añade ejemplos, igualmente semitizantes, de Bocados de oro y el Libro complido en los judicios de las estrellas. $M$ mantiene, sin embargo, «tronpeçadura», para la que Biblia Medieval registra dos ejemplos: Lv 19:14 de E3 [Aj] -único caso registrado en el CORDE- y Dn 11:34 de E7/E5 [Ev].

${ }^{48}$ estrumentes M: estormentos MH. Las abreviaturas del ms. hacen plausible nuestra lectura.

${ }^{49}$ enpeña E7/E5: esnpeña Biblia Medieval. El enlace al manuscrito digitalizado permite enmendar el error.

${ }^{50}$ estrumentes: estrumente $\mathrm{E} 7 / \mathrm{E} 5$; probable error de copia.

${ }^{51} e$ : es ms. E3. El uso aislado de «es» resulta incongruente; parece más lógico que la primitiva E3 se ajustara a TM (como E7/E5 [Ev] y $F$ ). Es también posible «[...] día de frío, $<\mathrm{e}>$ vinagre con greda, es el que canta [...]», en línea con $\tau$ E4 [BNE], Alba.
} 
F: Tirán paño en día de frío, (assí) vinagre sobre greda, y cantán en cantares sobre coraçón quebrantado.

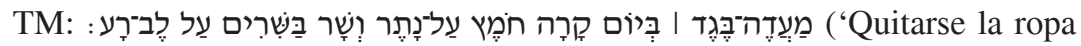
en día de frío [es como poner] vinagre en la llaga [lit.: 'nitro, sosa'] y cantar canciones a un corazón apenado').

$M$ comparte con E7/E5 [Ev] la novedad expresiva resultante del «enpeñar» los vestidos ${ }^{52}$ y de la transformación del acusativo interno de TM «canta cantares»-respetado por todos los romanceamientosen «canta con estrumentes», conservando el sentido de 'cantar alegremente'.

Sin embargo, la trasposición del tercer miembro del proverbio como segundo segmento de la oración que realiza $M$ no se da en ninguna otra biblia romanceada. El cambio parece una licencia excesiva para verlo como parte de la tradición textual de la biblia fuente de Palabras breves; cabe suponer, por tanto, que sea producto de la intervención del compilador, quien tal vez no le viera sentido a la bimembración original. Pudo, así, haber decidido reordenar los términos de la igualdad según un criterio típico de la tradición sapiencial: a un lado, las dos acciones humanas objeto de crítica por su insensatez; al otro, un término de comparación -una reacción química, a fin de cuentas- relacionado con la naturaleza.

E3 $\rightarrow \beta$ : «se tira» > «enpeña», «el» om., «con greda» > «sobre la greda», «canta cantares» $>$ «cantar con estrumentes», «mal» $>$ «triste».

$\beta \rightarrow$ E7/E5: «la ropa» $>$ «su ropa». $\beta \rightarrow$ Ev: «con estrumentes» $>$ «sobre estrumentes».- $\beta \rightarrow M$ : «sobre coraçón» > «con coraçón».

\section{0. (MH 132) Pr 25:21-22.}

qISi oviere fanbre $e^{53}$ el tu malqueriente ${ }^{54}$ dale a comer del pan, e si oviere sed dale a bever del agua, ca centellas pones sobre la tu cabeça e Dios te lo pechará. $(\cdot(\cdot(\cdot$

\footnotetext{
${ }^{52} C f$. E4 [BNE]: «quita la vestimenta»; Alba: «afeita e tira (o pierde) la vestimenta».

${ }^{53}$ fanbre [sic] M: fambre $\mathrm{MH}$.

${ }^{54}$ malqueriente M: malquerient' $\mathrm{MH}$.
} 
E7/E5 [Ev]: Si oviere fanbre el tu malqueriente dale a comer del pan e si oviere sed dale a bever del agua, [25:22] ca [Ev en] a[s]cuas conpones sobre la su [Ev tu] cabeça e el Señor te lo gualardonará.

E3: Si oviere fanbre tu enemigo dale a comer pan e si oviere sed dale a bever agua, [25:22] que brasas pones tú sobre su cabeça e el Señor lo pechará a ti.

$F$ : Si fambriento tu aborresciente, fazle comer pan; y si sequioso, fazle bever aguas. [25:22] Porque brasas tú ponién sobre su cabeça, y Adonay pagará a ti.

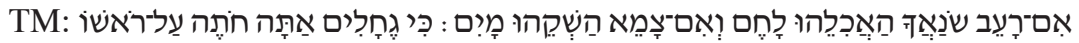

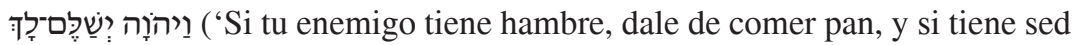
dale de beber agua; [25:22] así amontonarás brasas sobre su cabeza ${ }^{55}$ y Dios te lo pagará').

E3 $\rightarrow \beta$ : «enemigo» > «malqueriente».

$\beta \rightarrow \mathrm{E} 7 / \mathrm{E} 5$ [Ev]: «brasas» > «ascuas», «pones» > «conpones», «pechará»> «gualardonará». $-\beta \rightarrow \mathrm{Ev}$ «ca» $>$ «en» (error de copia). $-\beta \rightarrow M$ : «brasas»> «centellas» ${ }^{56}$. Por otra parte, $M$ y Ev son las únicas biblias romanceadas que presentan el erróneo «tu» por «su»; pero este aparente error conjuntivo podría también haberse dado en la fuente común $\beta$, y sólo E7/E5 lo habría advertido y corregido.

M om. Pr 25:23, que utiliza un elemento de la naturaleza -el ábrego portador de lluvia- como término de comparación.

\section{1. (MH 133) Pr 25:24.}

IIMás vale estar sobr'el ala del tejado que non con muger barajosa e fechizera. $(\cdot(\cdot(\cdot$

E7/E5 [Ev]: Más vale estar sobre ala de [Ev el alabe del] tejado que muger barajosa e casa de fechizera [Ev e fija de fechizero].

\footnotetext{
${ }^{55}$ Esto es, 'lo avergonzarás, le sacarás los colores'.

${ }^{56}$ En las biblias romanceadas, la palabra «centella» aparece en otros versículos (de Is, Ez, Sal, etc.), en general con el sentido de 'chispa, pavesa' o 'centella, rayo'. Sin embargo, en textos de otro tipo hay algún caso aislado en que quizás podría interpretarse, como en M, como 'ascua, brasa, tizón'; cf. Calila e Dimna (ca. 1251): «El omne sabio et de noble coraçón [...], la nobleza de su coraçón non quiere fueras parescer et mostrarse, así como la centella del fuego que omne asconde et ella non quiere sinon acenderse» (CORDE).
} 
E3: Mejor es estar en rincón de tejado que con mujer de roidos en casa de fechizo.

$F$ : Mejor estar sobre rincón de tejado, más que muger de barajas y en casa común.

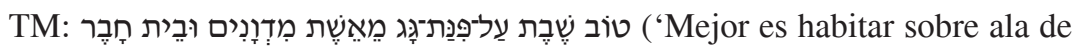
tejado que con mujer pendenciera y en posada' [lit. 'casa común, almacén']).

Oे $\mathrm{E} 3 \rightarrow \beta$ : «mejor» > «más vale», «rincón» > «ala de», «de roidos» $>$ «barajosa», «fechizo» $>$ «fechizera».

$\beta \rightarrow \mathrm{E} 7 / \mathrm{E} 5:$ «con» om. $-\beta \rightarrow \mathrm{Ev}$ : «ala» > «alabe», «casa de fechizera» $>$ «fija de fechizero» (fórmula con la que Ev racionaliza, redondeando su sentido misógino, el proverbio). $-\beta \rightarrow M$ : «casa de» om. Esta omisión puede deberse a un error del copista, o bien ser -como parece el caso de Ev- el resultado de la búsqueda de una mayor congruencia en la expresión. Los romanceamientos medievales de origen judío, ante la polisemia de TM חֶָָר / haber, que puede aludir tanto a lo comunitario como a la brujería y los encantamientos, optan unánimemente por esta última posibilidad; no lo hacen, por ejemplo, Vg («in domo communi») ni E8/E6 («en casa de común»), derivada de esta.

M om. Pr 25:25-26:3. Usan casi todos ellos términos de comparación sacados de la naturaleza, con la excepción de Pr 25:27, que repite la imagen de $\operatorname{Pr}$ 25:16, ya presente en Palabras breves, y 25:28, que recurre a una elegíaca evocación, casi paisajística, de ruinas urbanas ${ }^{57}$.

\section{2. (MH 134) Pr 26:4.}

IINon respondas al loco a su lucura ${ }^{58}$ por que non seas ${ }^{59}$ su igual. $(\cdot(\cdot$

E7/E5 [Ev]: Non respondas al nescio segund la su torpedat por que non semejes a él tanbién tú.

\footnotetext{
${ }^{57} C f$. E7/E5: «Cibdat abierta sin adarve es el varón que non ha detenimiento al su spíritu».

${ }^{58}$ lucura M: locura MH. Pero el CORDE atestigua «lucura» ya en los Milagros de Nuestra Señora (1246-1252) de Berceo.

${ }^{59}$ seas $M$ : seades $\mathrm{MH}$.
} 
E3: Non respondas al loco como su locura por que non te iguales con él tanbién tú.

$F$ : No respondas a loco como su locura, porque no seas igualado a él también tú.

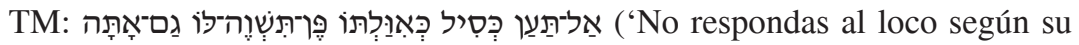
locura, para que no seas igual que él también tú’).

Divergencia total con respecto a E7/E5 [Ev]. $M$ se mantiene fiel a la línea tradicional, representada por $\mathrm{Vg}$ y los demás romanceamientos ${ }^{60}$, que asocia a un mismo lexema tanto el adjetivo sustantivado como el sustantivo sobre los que se articula la sentencia. Sin embargo, el uso de dos términos distintos se ajusta mejor a TM, que distingue ('estúpido, necio') e אְִֶ̣ / ivélet ('insensatez, necedad').

$M$ utiliza «a su lucura» donde todos los romanceamientos usan «segund/-t»; se trata de un probable error de transmisión, ya que en el proverbio siguiente, de formulación idéntica, $M$ conserva «según».

La supresión, como en Alba y Vg, del «también tú» pleonástico que conservan las otras biblias romances en la estela del «gam atá» de TM, puede ser obra de un compilador atento a mejorar la fluidez de su discurso.

$\mathrm{E} 3 \rightarrow \beta$ : no cambia.

$\beta \rightarrow$ E7/E5 [Ev]: «loco» > «nescio», «locura» > «torpedat», «te iguales» $>$ «semejes». $\beta \rightarrow M$ : «segund» $>$ «a», «te iguales con él» $>$ «seas su igual», «tanbién tú» om.

\section{3. (MH 135) Pr 26:5.}

IResponde al loco segund su locura por que non se tenga por sabio en sus ojos. $(\cdot(\cdot) \cdot$

E7/E5 [Ev]: E responde al [Ev responda $\mathrm{el}^{61}$ ] nesçio segunt su torpedat por que non se tenga por sabio en sus ojos.

E3: Responde al loco segund su locura por que non sea sabidor en sus ojos.

\footnotetext{
${ }^{60}$ Aparte de los citados, $c f$. E4: «nescio/nescedad»; en Vg: «stulto/stultitiam».

${ }^{61}$ responda el Ev: responda al Biblia Medieval. El enlace al manuscrito digitalizado permite enmendar el error.
} 
$F$ : Responde al loco como su locura, porque no sea sabio en sus ojos.

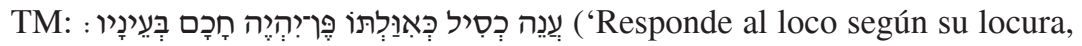
para que no se crea sabio' [lit. 'no sea sabio a sus ojos']).

\& La primera parte repite la divergencia con E7/E5 [Ev] del proverbio anterior.

E3 $\rightarrow \beta$ : «sea sabidor» > «se tenga por sabio».

$\beta \rightarrow$ E7/E5 [Ev]: «loco» > «nescio», «locura» $>$ «torpedat». $\beta \rightarrow$ Ev: además de las anteriores, «responde al» $>\langle$ responda el».- $\beta \rightarrow M$ : no cambia.

M om. Pr 26:6-11. Se trata de una serie de máximas que emplean, como término de comparación con el insensato -blanco crítico de la primera parte del capítulo-, acciones muy concretas y, ocasionalmente, de cierta crudeza $^{62}$. Su omisión permite retomar, en la sentencia que sigue, el tono de abstracción moral, y hasta la misma fórmula sintáctica, de las seleccionadas previamente.

\section{4. (MH 136) Pr 26:12.}

ISSi vieres omne que se tiene por sabio en sus ojos, más confiança ay en un loco que $e^{63}$ en él. $(\cdot) \cdot$

E7/E5 [Ev]: Viste omne que se tiene por sabio en sus ojos e ay más fiuzia en un nescio que en él.

E3: Si viste omne sabidor en sus ojos, esperança ay en el loco más que en él. $F$ : Si vieres varón sabio en sus ojos, esperança al loco más que de él.

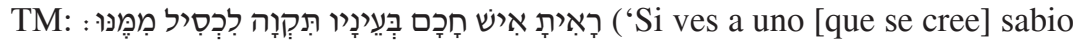
a sus ojos, confía más en el loco que en él’).

$M$ comparte con todos los romanceamientos la fórmula condicional; esta da fluidez narrativa al tono interrogativo original, aunque este

\footnotetext{
${ }^{62} C f$., por ej., Pr 26:7 en E7/E5 [Ev]: «Desconciértanse las caderas del coxo e el exenplo es en la boca de los nescios».

${ }^{63}$ que M: que no MH. Adición innecesaria; $c f$. E7/E5 [Ev] (también Alba: «Si vieres alguno que por sabio en sus ojos se tiene, mayor esperança ha en el loco que en él».
} 
se refleja, por otra parte, en la sintaxis un tanto sincopada de E7/E5 [Ev]; la coincidencia se repite, como en ocasiones anteriores, para «loco», que E7/E5 [Ev] vierte de nuevo como «nescio» ${ }^{64}$.

$M$ opta por «confiança»vs. «fiuzia», como ya hacía en $\operatorname{Pr} 25: 19$; las otras biblias coinciden con Vg («spem») al romancear «esperança» ${ }^{65}$.

$\mathrm{E} 3 \rightarrow \beta$ : «Si» om., «sabidor»> «que se tiene por sabio», «esperança» $>$ fiuzia», «el»> «un».

$\beta \rightarrow \mathrm{E} 7 / \mathrm{E} 5[\mathrm{Ev}]:$ loco» $>$ «nescio». $-\beta \rightarrow M:$ Viste» $>$ «Si vieres», «fiuzia» > «confiança».

M om. Pr 26:13-28:2. Lo omitido en Pr 26:13-16 se aplica al vituperio del perezoso, tipo que no parece interesar al compilador; el resto del capítulo mezcla la crítica de los cizañadores y chismosos con la de otro tipo social próximo, los hipócritas «que engañan en la sombra». La variedad de contenidos y formulaciones - de lo muy general a lo muy concreto- de Pr 27 no parece haber interesado al compilador, que prescinde también del muy genérico Pr 28:1 y del mašal que le sigue, cuyas implicaciones políticas podrían haberle parecido aplicables con demasiada evidencia a la desgobernada Castilla del momento ${ }^{66}$. Un fondo de implicación política alienta, sin embargo, en la sentencia que reanuda la colección, si bien esta se orienta, con lo que sigue de Pr 28, hacia la contraposición entre ricos y pobres.

15. (MH 137) Pr 28:3.

IEl que fuerça a los menesterosos es como la luvia rauda que non aprovecha. $(\cdot(\cdot$

${ }^{64}$ Aquí para TM כְְִּּ / kesil ('necio, estúpido'). Es habitual que frente a E3 «loco», E7/ E5 [Ev], E4 [BNE] lean «nescio» (con Vg: «stultus»), con Alba alternando ambas formas. Nótese que el término «loco» sirve también en Pr para romancear TM אֶו̣ / evil ('loco' propiamente dicho) y נבָָ / nabal ('tonto').

${ }^{65}$ Como muestra del peculiar estilo formulaico de composición de este tipo de obras, cabe observar que todos los romanceamientos repiten sus respectivas versiones de $\mathrm{Pr}$ 26:12 [b] en 29:20 [b]. $C f$., por ej., E3: «Si viste omne quexoso en sus palabras, esperança ay en el loco más que en él»; E7/E5: «Verás varón acucioso en sus palabras e ay más fiuza en el necio que en él».

${ }^{66} C f$., por ej., la versión de Alba: «Por pecado de la tierra son muchos los sus príncipes, pero por causa de algund omne prudentíssimo e sciente se aluenga el mal». 
E7/E5 [Ev]: El barragán [Ev add. pobre] que roba a los menesterosos es como la lluvia radia que non aprovecha.

E3: El ome pobre e robador de mezquino, como lluvia que corre e non ay pan. $F$ : Varón pobre y sobreforçán mendigos, lluvia arrabdonán y no pan.

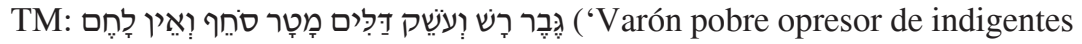
es como lluvia torrencial que arrasa y [deja] sin pan').

$M$ sí conserva aquí un proverbio cuyo término de comparación se toma de la naturaleza. E7/E5 es el único romanceamiento que omite «pobre» (TM רָ / raš), como hace $M$. Puede ser un error de transmisión en ambos casos, pero igualmente puede deberse a decisiones conscientes: en E7/E5, al mantener «barragán» para traducir TM גֶֶֶּ / guéber (que permite la doble lectura 'varón' 'valiente, poderoso' ${ }^{67}$ ), conservar «pobre» pareció quizá incongruente. La fuente bíblica de $M$ pudo, a su vez, optar por la salomónica solución de prescindir de ambos términos.

En cuanto a «rauda», si no es un error de copia del compilador, parece reflejar -aunque no altere mucho el sentido de la frase- la falta de comprensión de «radia» ${ }^{68}$, voz exclusiva de la familia E7/E5 [Ev] que, aunque utilizada para traducir varios términos hebreos, se asocia siempre a aguas o lluvias torrenciales, tanto aquí como en Is 28:2, Ez 38:22 o en Sal 124:4 (5) ${ }^{69}$.

E3 $\rightarrow \beta$ : «ome»> «barragán», «mezquino»> «menesterosos», «que corre» $>$ «radia», «e non ay pan» $>$ «que non aprovecha».

$\beta \rightarrow$ E7/E5: «pobre» om. $\beta \rightarrow$ Ev: no cambia.- $\beta \rightarrow M$ : «barragán pobre» om., «roba» $>\left\langle\left\langle\right.\right.$ fuerça ${ }^{70}$, $\langle$ radia» $>\langle$ rauda».

\footnotetext{
${ }^{67}$ Los demás romanceamientos también se dividen: E4 [BNE]: «varón» (con Vg: «vir»); Alba: «poderoso».

${ }^{68}$ No «radía» cuyo sentido ('suelta, dispersa') no se ajusta al del proverbio. Para «radio, -a» y su posible relación con el cat.-oc. rajar ('correr un líquido, chorrear'), $c f$. CoroPASC, s. v. RAYO.

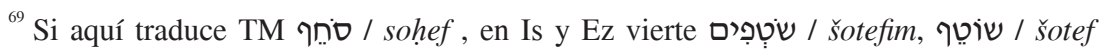
('torrencial, impetuoso'), respectivamente; y en el muñón de Sal 124:5 que se injerta en 124:4, הַזּודרוֹנִים / ha-zedonim ('soberbias, altivas').

${ }^{70}$ Las biblias castellanas mantienen, en formas diversas, «robar» (cf. E4 [BNE]: «robante»; Alba: «que roba»); «el que fuerça» se acerca quizás mejor a TM עتِّ / 'ošec ('opresor').
} 
16. (MH 138) Pr 28:4.

ILos que desmanparan la Ley loan al malo e los que guardan Ley conbaten con ellos. $(\cdot(\cdot /[$ Fol. $84 r(\mathrm{LXXXVIr})]$

E7/E5 [Ev]: Los que desanparan la Ley alaban al malo e los que guardan la Ley conbaten con ellos.

E3: Los que dexan la Ley alaban al malo e los que guardan la Ley se conbaten con ellos.

F: Dexantes Ley, alaban malo; y guardantes Ley, combaten con ellos.

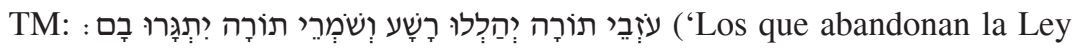
alaban al impío y los que guardan la Ley se indignan [lit. 'se lanzan, atacan'] contra ellos').

Primer proverbio de estructura bimembre, paralelística y antitética recogido por el compilador; es del tipo «A hace $x$ [pero] -A hace $-x{ }^{71}$.

E3 $\rightarrow \beta$ : «dexan» > «desanparan» (que incide en la dimensión moral del abandono de la Ley), «se» om.

$\beta \rightarrow$ E7/E5 [Ev]: no cambian.- $\beta \rightarrow M$ : «desanparan» > «desmanparan», «alaban» > «loan»; la omisión del segundo «la» parece un despiste del compilador.

\section{7. (MH 139) Pr 28:5 [a].}

$\mathbb{I}\left[\right.$ Los om $[n e] s^{72}$ malos non entienden el derecho.

E7/E5 [Ev]: Las personas maliciosas non entienen el derecho.

E3: Los omnes malos non entienden el juizio.

$F$ : Varones de mal no entienden juizio.

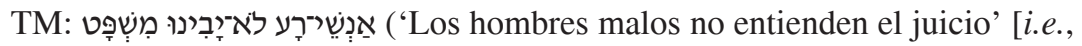
'la Ley o recto juicio (divino)']).

Al dividir el proverbio bíblico, $M$ rompe el paralelismo antitético original, al tiempo que se acerca a la tónica marcada por la primera sección de Palabras breves, que rehuye los paralelismos.

\footnotetext{
${ }^{71}$ Vid. Alba y SAInZ de la MAZA, «Amóstrame Gan Eden», págs. 57 y 59. Remitimos a este trabajo a los interesados en la tipología de los restantes ejemplos paralelísticoantitéticos de $M$.

${ }^{72}$ omnes: oms $M$ con tilde de abreviatura.
} 
E3 $\rightarrow \beta$ : «juizio» > «derecho».

$\beta \rightarrow \mathrm{E} 5 / 7$ [Ev]: «omnes malos» > «personas maliciosas».

$M$ no sigue aquí la tendencia innovadora de E7/E5 y comparte la selección léxica común a las otras biblias romanceadas, que calca TM / אַנְשְׁי־רָע / 'anšé-ra' ('hombres malos'), en sintonía con su preferencia por la expresión sencilla y directa.

18. (MH 140) Pr 28:5[b].

ILos que buscan a Dios entienden todo.

E3, E7/E5 [Ev], E4 [BNE]: e los que buscan al Señor entienden todo.

$F$ : y buscantes Adonay entienden todo.

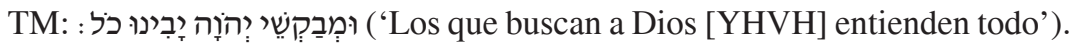

$\&$ La totalidad de los romanceamientos transcriben el nombre divino como «Señor»; el uso de «Dios» en nuestra antología nos recuerda que, aun siendo obra de un converso, Palabras breves surge en un contexto cristiano-nuevo no conflictivo en lo doctrinal.

\section{9. (MH 141) Pr 28:6.}

IIMás vale ser pobre e andar en sanidad que duro de costunbres e ser rico. (• E7/E5 [Ev]: Más vale pobre andar en la su sanidat que endurescido de carreras e el ser rico.

E3: Mejor es el pobre que anda sanamente qu'el que atuerce sus caminos e es rico.

F: Mejor pobre andán en su perfición, más que perverso de carreras y el rico.

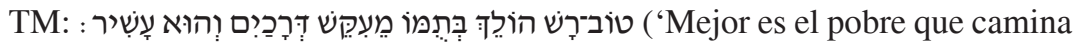
en su integridad que el de tortuosas vías [o 'costumbres, conducta, etc.'] aunque sea rico').

Sentencia de organización paralelística y antitética, forma proverbial a la que Palabras breves va a ir abriéndose gradualmente a partir de ahora. La expresión «duro de costunbres» es la única, entre los romanceamientos conservados, que se distancia del metafórico «pravis itineribus» de $\mathrm{Vg}$; parece, de nuevo, producto de la tendencia de $M$ a la sencillez expresiva. 
E3 $\rightarrow \beta$ : «Mejor es» > «Más vale (ser)», «el que atuerce sus caminos» $>$ «endurescido de carreras», «es» $>$ «el ser».

En cuanto a «anda sanamente» es tal vez un cambio más reciente, propio de la versión conservada de E3 y no de su matriz; se aleja de, y moderniza, un presumible «andar en su sanidad», más cercano a TM הוֹלֵק

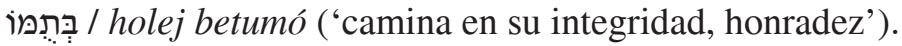

$\beta \rightarrow \mathrm{E} 7 / \mathrm{E} 5:$ «el» $a d d .-\beta \rightarrow \mathrm{M}$ : «ser» add., «endurescido de carreras» $>$ «duro de costunbres».

20. (MH 142) Pr 28:7.

IEl que guarda la Ley es fijo entendido e el que acompaña a los tragones envergüença a su padre. $(\cdot(\cdot$

E7/E5 [Ev]: El que guarda la Ley es fijo entendido e el que aconpaña a los tragones envergüençç ${ }^{73}$ a su padre.

E3: El que guarda la Ley es fijo entendido e el que govierna a los tragones avergüença a su padre.

F: Guardán Ley, hijo entendido; y compañero de tragones avergüença su padre.

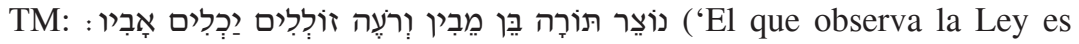
hijo inteligente, el que frecuenta a los libertinos [o 'alimenta a los glotones/ lascivos'] deshonra a su padre').

$\Longleftrightarrow \mathrm{E} 3 \rightarrow \beta$ : «govierna» > «aconpaña ${ }^{74}$, «avergüença» > «envergüença».

$\beta \rightarrow$ E7/E5 [Ev], $M$ : no cambian.

\footnotetext{
${ }^{73}$ envergüença E7/E5, Ev: en vergüenza Biblia Medieval . El enlace a los manuscritos digitalizados permite subsanar el error.

${ }^{74}$ E3 optaba al traducir TM רעֶ / ro'é por la primera acepción de la raíz רעה / ra'á ('alimentar, dar forraje al ganado'), en la misma línea de Alba o Vg, y de modo congruente con el «tragones» que le sigue. La sustitución acerca el texto a un nivel de comprensión más actual, centrado en el sentido moral abstracto del proverbio y en la línea del comentario de Raší al mismo ( רעֶׁ indica 'amistad'»). El resto de los romanceamientos, sin embargo, se mantuvo fiel -como Vg: «qui pascit comesatores»a la sugestiva concreción de la imagen original; así, E4 [BNE], Alba: «el que mantiene los tragones [BNE a glutones]».
} 
M om. Pr 28:8. Suprime un proverbio que rompía la pauta 'quien se desvía moralmente, queda negativamente marcado', la cual se retoma en 28:975.

\section{1. (MH 143) Pr 28:9.}

IEl que aparta su oreja de oír Ley, la su oración es aborrescida. $(\cdot(\cdot$

E7/E5 [Ev]: El que aparta la su oreja de oír Ley, tanbién la su oración es aborrescida.

E3: El que tira su oreja de oír la Ley, aun su oración es aborrescida.

F: Apartán su oreja de oír Ley, también su oración abominación.

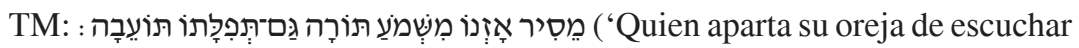
la Ley, también su oración es aborrecida').

$\bigotimes \mathrm{E} 3 \rightarrow \beta:$ «tira» > «aparta», «aun» > «tanbién», «la» om., (último) «la» add.

$\beta \rightarrow$ E7/E5 [Ev]: (primer) «la» add.- $\beta \rightarrow$ M om. «tanbién», aligerando el ritmo sintáctico al prescindir del elemento enfático presente en TM 미 / gam ('también'; $c f$. CANT-IGL: «su oración misma»).

M om. Pr 28:10-13. Todos de organización paralelística antitética. El compilador parece haber buscado continuar con un proverbio que enlace con la idea del castigo reservado al impío, prefiriendo Pr 28:14 a los también posibles $\operatorname{Pr} 28: 10$ o 28:13 ${ }^{76}$.

\section{2. (MH 144) Pr 28:14.}

I[Bienaventurado es el omne que sienpre ha themor, e el que enduresce su coraçón sobr'él cahe su mal. $(\cdot(\cdot$

E7/E5 [EV]: Bienaventurado es el omne que teme sienpre e el que enduresce su coraçón cuando [Ev om. cuando] cae en el mal.

\footnotetext{
${ }^{75} C f$. Pr 28:8 en E7/E5: «El que multiplica su algo a logro e usura, para se apiadar a los pobres lo allega».

${ }^{76} C f$., en E7/E5, Pr 28:10: «El que diestra a los derechos por mal camino, en la su danificación él mesmo cahe; e los que son a buena parte, heredan el bien»; Pr 28:13: «El que encubre su pecado non es perdonado, e el que manifiesta e se dexa es piadado». $\operatorname{Pr}$ 28:14 desarrolla idéntica contraposición, pero en orden inverso.
} 
E3: Bienaventurado es el omne que teme siempre; e el que enduresce su coraçón caerá en mal.

$F$ : Bienaventurado hombre espavorescién continuo, y endurescién su corazón caerá en mal.

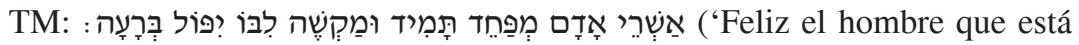
siempre temeroso; y el que endurece su corazón, caerá en la desgracia/en el mal').

\& $3 \rightarrow \beta$ : «caerá»> «cae», optando, como Alba, por una correlación 'presente-presente'.

$\beta \rightarrow \mathrm{E} 7 / \mathrm{E} 5:$ «cuando» $a d d$., error de interpretación que no se da en ningún romanceamiento. $-\beta \rightarrow$ Ev: no cambia. $-\beta \rightarrow M$ : «cae en el mal»> «sobr'él cahe su mal», opción que matiza, reforzando sus connotaciones éticas, el sentido original.

M om. Pr 28:15-18. Se suprime un proverbio asociado a la naturaleza, otro de organización paralelística antitética, un tercero desarrollado mediante una bimebración consecutiva ${ }^{77}$ y un cuarto también antitético.

\section{3. (MH 145) Pr 28:19.}

IEl que labra su tierra fártase de pan e el que usa con los vazíos hártase de pobredad $^{78} \cdot(\cdot(\cdot$

E7/E5 [Ev]: El que labra la su tierra será farto de pan e el que usa con los bazíos [Ev vizios] será farto de pobreza.

E3: El que labra su tierra se fartará de pan, e el que sigue vanidades se fartará de proveza.

F: Labrán su tierra, se fartará de pan; y siguién vagabundo, se fartará de pobreza.

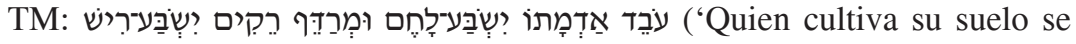
sacia de pan; el que sigue a los [hombres] vanos se saciará de pobreza').

\footnotetext{
${ }^{77}$ Esto es, del tipo «Si A hace $x$, se siguen $y$ e $y^{\prime} » ;$ vid. Alba y SAINZ de la MazA, «Amóstrame Gan Eden», págs. 57-58 y 61.

${ }^{78}$ hártase de pobredad M: fártase de probredad $\mathrm{MH}$.
} 
$\mathrm{E} 3 \rightarrow \beta$ : «se fartará» > «será farto», «sigue vanidades» > «usa con los vazíos» ${ }^{79}$, «proveza» > «pobreza».

$\beta \rightarrow$ E7/E5: no cambia. $-\beta \rightarrow$ Ev: «vazíos» $>$ «vizios».- $\beta \rightarrow$ M: tiempo verbal futuro $>$ presente, «pobreza» $>$ «pobredad».

\section{4. (MH 146) Pr 28:20.}

IIEl omne de fianças es de mucha bendición, e el que es quexoso por riqueza non puede ser linpio. $(\cdot(\cdot$

E7/E5: El varón de verdades avrá [Ev averá] bendición, e el que es acucioso por la riqueza non será perdonado.

E3: El omne de verdades avrá muchas bendiciones e el que es quexoso para enriquecer non será libre.

$F$ : Varón de verdades, grande de bendiciones; y apressurán para enriquecer, no será quite.

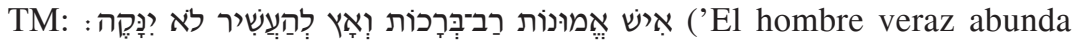
en bendiciones, el que se apresura a enriquecerse no quedará impune [o 'limpio']').

Aunque no presenta un paralelismo antitético estricto, la frase que forma el segundo miembro de la sentencia repite en forma negativa la organización del primer miembro de la misma.

E3 $\rightarrow \beta$ : «muchas bendiciones» > sing., «para enriquecer» > «por riqueza».

$\beta \rightarrow$ E7/5 [Ev]: «omne» > «varón», «mucha» om., «quexoso» > «acucioso», «libre» > «perdonado». $\beta \rightarrow M$ : «es» > «avrá», «verdades» $>$ «fianças», «será libre» > «puede ser linpio», y mantiene el tiempo verbal en presente en los dos miembros de la sentencia, frente al resto de romanceamientos ${ }^{80}$.

\footnotetext{
${ }^{79}$ vanidades ms. E3: podríamos tal vez conjeturar que es producto de una mala transmisión textual, banalizando un posible «sigue vaziedades» del romanceamiento matriz de E3.

${ }^{80}$ El resultado final presenta ciertas coincidencias con E4 [BNE]: «El omne de firmezas [BNE firmesas] es de muchas bendiciones e el que acucia para enriquescer non se alinpiará».
} 
M om. Pr 28:21. Tal vez eliminado porque interrumpe el hilo temático, retomado con $\operatorname{Pr} 28: 22$, del afán de riqueza del malo ${ }^{81}$.

\section{5. (MH 147) Pr 28:22.}

IQuéxase por la riqueza el varón de mal ojo e non entiende que ha ${ }^{82}$ de venir a mengua. ( •

E7/E5 [Ev]: Túrbase por el algo el varón del mal ojo e non sabe que a mengua le $[\mathrm{Ev} \mathrm{lo}]$ ha de traher.

E3: El que se atorva por el aver es omne malo de ojo e non sabe que mengua le verná.

Ferr:: Apressúranse por aver, malo de ojo, y no sabe que mengua le verná.

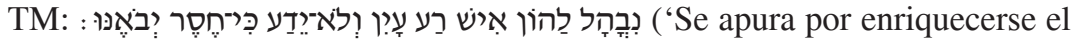
hombre avaro [lit. 'de mal ojo'] y no sabe que le llegará la miseria').

Es esta una de las sentencias en que $M$ más se aparta de los romanceamientos conservados, excepto en el uso de «de mal ojo» y «mengua». El conjunto parece favorecer un tono de mayor sencillez estilística.

E3 $\rightarrow \beta$ : cambia la literalidad de la frase copulativa; igualmente, «atorvarse» > «turbarse», «omne» > «varón»; tal vez «aver» > «algo». $\beta \rightarrow \mathrm{E} 7 / \mathrm{E} 5$ [Ev]: «mengua le verná»> «a mengua le [Ev lo] ha de traer». $\beta \rightarrow M$ : «turbarse» > «quexarse» (i. e., 'aquejarse, afanarse'), «algo» > «riqueza» ${ }^{83}$, «saber» $>$ «entender», «mengua le verná» > «ha de venir a mengua».

\footnotetext{
${ }^{81}$ Aquí el proverbio es una reflexión sobre toda la condición humana; $c f$. E7/E5: «Conoscer fazes non es bien, e por un çatico de pan peca omne». Es, a la vez, un buen ejemplo de cómo producir un paralelismo de sentido mediante la yuxtaposición de los dos miembros de la sentencia: el segundo le infunde al primero su sentido de 'mostrar parcialidad hacia los conocidos es malo', lo transforma en su consecuencia: «Como uno se vende por un mendrugo $[\ldots] »$.

${ }^{82}$ ha $\mathrm{M}$ : era $\mathrm{MH}$.

${ }^{83}$ En la sentencia anterior, $M$ empleaba también «ser quexoso» y «riqueza». Esta última moderniza «el algo», que, como indican CORO-PASC, fue quedando relegado en el siglo XV a textos jurídicos y homiléticos, a algún romanceamiento (incluyendo la parte bíblica de Las bienandanças e fortunas) y algún libro caballeresco como El conde Partinuplés. La misma dualidad «algo / riqueza» está presente en la familia de romanceamientos BNE-E4, respectivamente.
} 
26. (MH 148) Pr 28:23.

IIEl que castiga al omne, después alcança gracia más qu'el lisonjero de lengua. $(\cdot(\cdot$

E7/E5 [Ev]: El que riepta al omne, después gracia alcança más que el lisongero de lengua.

E3: El que castiga a omne, después gracia alcançará más qu'el que falaga con la lengua.

Ferr.: Reprehendién hombre, después gracia fallará, más que alisán lengua.

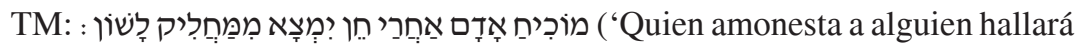
después más gracia que el que halaga con la lengua').

E3 $\rightarrow \beta:$ : «a» > «al», «alcançará» > «alcança», «falaga con la» > «lisonjero de».

$\beta \rightarrow$ E7/E5 [Ev]: «castiga» > «riepta» (que aporta matices de mayor dureza). $-\beta \rightarrow M$ : «gracia alcança» > «alcança gracia», en aras de una mayor sencillez expresiva.

\section{7. (MH 149) Pr 28:24.}

IEl que roba a su padre e a su madre e dize: «Non fago pecado», es igual del omne dañador. $(\cdot(\cdot$

E7/E5 [Ev]: El que roba a su padre e a su madre e dize: «Non yerro», conpañero es del varón dapnificador.

E3: El que roba a su padre e a su madre e dize: «Non es pecado», conpañero es del señor dapñador.

$F$ : Robán su padre y su madre, y dizién: «No rebello», compañero él de varón dañador.

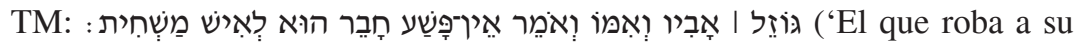
padre y a su madre y dice: «No es pecado», [es] compañero del hombre devastador').

$M$ se distingue de los demás romanceamientos por el empleo de «fago»e «igual», que sacrifica la literalidad del universal «conpañero» 
(TM חָָבר / haber 'compañero, socio, amigo') en favor de su preferencia por un lenguaje sencillo y directo ${ }^{84}$.

E3 $\rightarrow \beta$ : no cambia; si acaso, «señor ${ }^{85}$ dapñador» > « omne dañador».

$\beta \rightarrow$ E7/E5 [Ev]: «es pecado»> «yerro», «omne dañador»> «varón dapnificador». $-\beta \rightarrow M$ : «es» $>$ «fago», «conpañero» > «igual».

\section{8. (MH 150) Pr 28:25-2686.}

IIEl que ha furioso el espírito ${ }^{87}$ rebuelve roido e el que ha confiança en Dios es deleitoso; [28:26] el que se confía con su ${ }^{88}$ coraçón es loco; el que anda con saber, aquel escapa $<\left(\cdot>^{89}\right.$.

E7/E5 [EV]: La sobejanía de la voluntad enciende roido [Ev ruido] e la fiuza [Ev fiuzia] del Señor deleita [Ev adeleita]. [28:26] El que afiuza en su coraçón es nescio; el [Ev e el] que anda con sabiduría, éste [Ev ese] escapa.

E3: El que es largo de ánima enciende roido e el que se enfuzia sobr'el Señor será aviciado. [28:26] El que se enfuzia en su coraçón es loco; e el que anda con saber, aquel escapará.

F: Ancho de ánimo, mescla baraja; y confián en Adonay será aviciado. [28:26] Confián su coraçón, él loco; y andán con sciencia, él escapará.

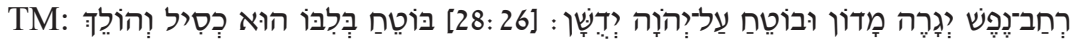
: El codicioso [lit. 'ancho de ánimo / de alma'] provoca peleas; el que confía en el Señor, prosperará. [28:26] El que confía en su inteligencia [lit. 'corazón', i. e. 'en sí mismo'] es un loco; el que camina en sabiduría, se salva').

\footnotetext{
${ }^{84} M$ no llega, sin embargo, a la soltura casi coloquial que logra en este pasaje R. Mošé Arragel; $c f$. Alba: «El que roba a su padre e a su madre e dize: "Non he pecado", aquel tal es conpañero de las malas personas».

${ }^{85}$ señor: una inusual traducción de TM אִיש / 'iš ('hombre, varón', que prefieren las biblias castellanas), tal vez ausente de la matriz de E3.

${ }^{86} M$ no separa ambos versículos; van seguidos.

${ }^{87}$ espírito M: escudo $\mathrm{MH}$.

${ }^{88}$ su M: om. MH.

${ }^{89}$ ( $\bullet$ : om. M, pero el texto llega hasta el final de la caja de escritura, por lo que no consideramos esta y la siguiente sentencia como una unidad; el aparente macroproverbio no puede leerse como el resultado de una intervención del compilador.
} 
\& El compilador retoma aquí los proverbios de paralelismo antitético, enlazando dos versículos mediante el nexo que se establece entre «confiança» $\mathrm{y}$ «se confía». Al optar por el término «Dios» frente al casi seguro «Señor» de su fuente, apunta, una vez más, al medio social cristiano - de integración conversa- en el que se enmarca la colección.

Este es uno de los casos en que $M$ muestra una tendencia a la originalidad comparable a la de sus hermanas E7/E5 [Ev], ya que se aparta de todos los romanceamientos conocidos ${ }^{90}$; es interesante, a este respecto, la diferente forma en la que expresan la violencia asociada - por el propio contexto del proverbio- a la figura del codicioso, una connotación que quizá se hallaba ya presente en su antecesor $\beta$.

E3 $\rightarrow \beta$ : «será aviciado»> «es deleitado ${ }^{91} »$, «enfiuza»> «afiuza», «escapará» > «escapa».

$\beta \rightarrow$ E7/E5 [Ev]: «El que es largo de ánima» > «La sobejanía de la voluntad», «el que [...] deleitado» > «la fiuza del Señor deleita», «loco» $>$ «nescio», «saber» $>$ «sabiduría», «aquel» $>$ «este [Ev ese]».- $\beta \rightarrow$ $M$ : «es largo de ánima» > «ha furioso el espírito», «enciende» $>$ «revuelve», «deleitado» > «deleitoso», «afiuza»> «confía»; y, como en 130/Pr 25:19, «fuzia» > «confiança».

\section{9. (MH 151) Pr 28:27.}

$\left[\mathbb{T I}^{92}\right.$ El que da al pobre non avrá mengua, e los que alçan sus ojos han muchas vistas. $(\cdot(\cdot$

E7/E5 [Ev]: El que da al pobre non alcança [Ev averá] mengua; el [Ev e el] que encela sus ojos ha grande [Ev grant] pavor.

\footnotetext{
${ }^{90}$ La expresión «espíritu furioso» aparece una sola vez, en 2S 22:16 de E7/E5, pero

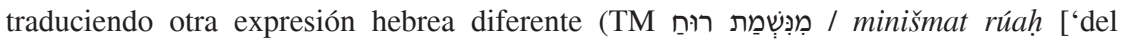
resoplido de la respiración']): «E parescen las fonduras de las aguas e descúbrense los cimientos del mundo, de la tu tenpesta, Señor, e del espíritu furioso de la tu ira».

${ }^{91}$ Podría ser también ya «deleitoso», como en $M$; pero privilegiamos la conservación del participio, como en E4 [BNE]: «será deleitado [BNE delectado]».

${ }^{92}$ II: om. M. A pesar de la ausencia de marcas de separación, no hay continuidad en cuanto al contenido con la sentencia anterior; cf. supra, n. 86 .
} 
E3: El que da al pobre non le menguará, e el que encubre sus ojos avrá mucha mengua

F: Dán a necessitados, no falta; y a encubrién sus ojos, muchedumbre de maldiciones.

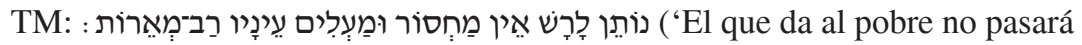
necesidad; el que cierra sus ojos, abundará en maldiciones').

Aunque está enmascarado por la traducción defectuosa, el proverbio aquí seleccionado es también de tipo paralelístico-antitético. La llamativa fórmula «los que alçan los ojos han muchas vistas» -que en otro contexto resultaría cómicamente irónica- está ausente de todos los romanceamientos conservados y constituye un error que, en apariencia, separa a $M$ del conjunto E5/7 [Ev]. Tal vez pueda relacionarse con una mala lectura del «encelan» (éçelā) -que sí conservarían E7/E5 [Ev]- de la fuente que se copia:

E3 $\rightarrow \beta$ : «le menguará» > «avrá mengua», «encubre» > «encela».

$\beta \rightarrow$ E7/E5: «avrá» > «alcança» $y$, con Ev, «avrá mucha mengua» > «ha grande pavor $»^{93} .-\beta \rightarrow M$ : «el» $>\langle$ los», «encela» $>\langle-\mathrm{n} »$.

Es difícil de aceptar que la perogrullesca y absurda conclusión de la sentencia sea obra de ningún romanceador bíblico consciente de su tarea, por lo que proponemos considerarla como una corrección del compilador de Palabras breves: es posible que en el ejemplar del que éste copiaba faltara o resultara ilegible el final del versículo; el compilador leería, así, mal, eç̧ela (-o, incluso, tal vez, un ya erróneo «acelan» (açelā)-los ojos > alçan los ojos ${ }^{94}$, y supliría el final con

\footnotetext{
${ }^{93}$ E7/E5 [Ev] sí hacen honor aquí a su gusto por lo original, que, en este versículo, exhibe también algún otro traductor, como R. Mošé Arragel, quien -haciendo gala de un gusto por el matiz que muestra en muchos lugares de su versión y que aquí parece adaptar el צִדָָָָ / ședacá (en el sentido de 'caridad, donativo') que Raší inserta en su glosapuntualiza en Alba: «Quien diere pitança al pobre [...]».

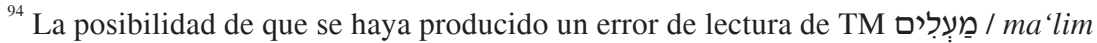

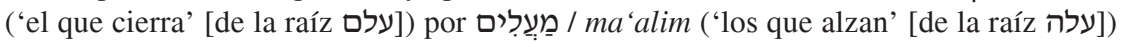
es, por obvia, muy atractiva; sin embargo, es complicado armonizarla con la tesis que planteamos. La confusión tendría que haberse producido, probablemente, durante la redacción de $\beta$, cuyo autor no habría cotejado su lectura con la de E3; al romancearse luego E7/E5[Ev], habrían advertido y enmendado el error. Este habría perdurado en $M$, pasando a Palabras breves con el efecto ya señalado sobre el final del versículo.
} 
una lógica sapiencial un tanto ramplona, en la que habría podido pesar quizás de algún modo la pareja «alçar/esconder» del inmediato $\operatorname{Pr} 28: 28$.

\section{0. (MH 152) Pr 28:28.}

I[Con el alçamiento del malo se esconde el omne e con la su prisión multiplican los justos. $(\cdot(\cdot /[$ Fol. $84 v($ LXXXVI $v)]$

E7/E5 [Ev]: Con el enfestamiento de los malos se encubre el omne e con la su perdición multiplican los justos.

E3: Cuando se levantan los malos se encubren el omne e cuando se pierden crescen los justos.

$F$ : En levantarse malos se encubre hombre, y en su perderse se multiplican justos.

TM: : Cuando se alzan los malvados, se esconde el hombre, cuando desaparecen [lit. 'se pierden'], se multiplican los justos').

\& De nuevo, un proverbio paralelístico y antitético. Ningún romanceamiento emplea «alçamiento» ni «prisión». Esta (ms. prisyon) es probable mala lectura de «perdición» (ms. E5 perdiçyon), más cercana que esta a lo cotidiano. Si no se trata de un error de copia del compilador de Palabras breves, es lectura separativa de $M$ frente a E7/E5 [Ev] ${ }^{95}$.

$\mathrm{E} 3 \rightarrow \beta$ : «cuando se levantan» $>$ «con el enfestamiento» ${ }^{96}$, «cuando se pierden» $>$ «con la su perdición», «crescen» $>$ «multiplican».

$\beta \rightarrow$ E7/E5 [Ev]: no cambia. $-\beta \rightarrow M$ : «enfestamiento» $>$ «alçamiento», «malos» > «malo», «encubre»> «esconde», «perdición»> «prisión».

\footnotetext{
${ }^{95}$ Por su parte, BNE y Alba usan también «cuando se pierden»; E4 prefiere «se destruyen».

${ }^{96}$ enfestamiento: podría también ser levantamiento, más cercano a E3 y usado en algún caso en los romanceamientos bíblicos con ese mismo sentido moral y social añadido al puramente físico (por ejemplo en Lv 26:37, en que E3 y Aj usan precisamente «enfestamiento»). En cambio, alçamiento, aunque es frecuente en las biblias castellanas, no se usa nunca de esa manera, por lo que parece innovación de $M$.
} 
31. (MH 153) Pr 29:1[a].

IIEl varón que muchas vezes lo castigan es duro de cerviz $<\left(\cdot>^{97}\right.$.

E7/E5 [Ev]: El varón de muchos castigos es duro de cerviz\{; a sobreora es quebrantado $\sin ^{98}$ melezina .

E3: El omne que a los castigos enduresce la cerviz\{, a sobrevienta se quebrará sin quien lo melezine\}.

$F$ : Varón de reprehensiones endurescién cerviz\{, súbito será quebrantado y no melezina\}.

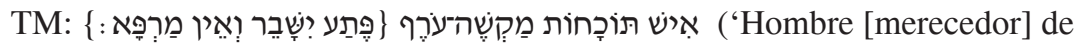
amonestaciones [que] es duro de cerviz\{, inesperadamente [será] quebrado, y no [habrá] cura\}').

La omisión de la marca de fin de sentencia, « (• », podría interpretarse como una señal de que el copista se salta inadvertidamente Pr 29:1[b]; sin embargo, no parece ser así, sino que más bien estamos ante un caso de corte por parte del compilador del proverbio que copia, sin que -al revés de lo que hará en la sentencia 34- forme con su segunda mitad una máxima aparte, tal vez porque Pr 29:1[b] no posee la estructura adecuada para funcionar independientemente -y también, probablemente, porque desciende a lo material y concreto. El recorte desvía el sentido del texto de la correlación 'mal moral $\rightarrow$ castigo inevitable' hacia el ámbito de la reflexión caracteriológica: 'si amonestan a alguien continuamente, su terquedad muestra su estupidez', creando así una sentencia muy del gusto de las colecciones sapienciales tradicionales.

$\mathrm{E} 3 \rightarrow \beta$ : «omne» > «varón», «que a los castigos» > «de muchos castigos», «enduresce» $>$ «es duro» ${ }^{99}$.

$\beta \rightarrow$ E7/E5 [Ev]: no cambian ${ }^{100} .-\beta \rightarrow M:$ «de muchos castigos» > «que muchas vezes lo castigan».

M om. 29:1[b].

\footnotetext{
${ }^{97}(\cdot$ : om. M. Pero la sentencia llega al borde de la caja de escritura (como en el núm. 29/ Pr 28:27). Para el proverbio completo, $c f$. CANT-IGL: «Hombre que ante las amonestaciones endurece la cerviz, | de súbito y sin remedio será quebrantado».

${ }^{98} \sin$ Ev: sy Biblia Medieval; el enlace al manuscrito permite subsanar el error.

${ }^{99}$ En Pr 29:1[b], «sobrevienta» > «sobreora», «se quebrará» > «es quebrantado», «sin quien lo melezine» > «sin melezina».

${ }^{100}$ En Pr 29:1[b], $\beta \rightarrow$ Ev: $\ll \sin »>\ll$ si $»$.
} 
32. (MH 154) Pr 29:2[a].

IICon los muchos justos se alegra el pueblo ${ }^{101}$. ( •

E7/E5 [Ev]: Con los muchos justos se alegra el pueblo [...].

E3: Cuando cresçen los justos se alegra el pueblo [...].

$F$ : En enseñorear justos se alegrará el pueblo [...].

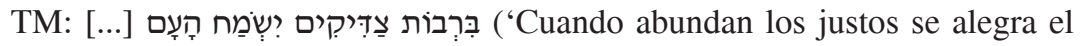
pueblo, $\left.[\ldots]^{\prime}\right)$.

Caso de división del proverbio en dos máximas; rompe el paralelismo antitético original.

E3 $\rightarrow \beta$ : «Cuando crescen» $>$ «Con los muchos».- No hay cambios ulteriores en E7/E5, Ev o $M$.

\section{3. (MH 155) Pr 29:2[b].}

IICon el enpoderamiento ${ }^{102}$ del malo entristeze el pueblo. $(\cdot$

E7/E5 [Ev]: [...] e con el señorío del malo entristece el pueblo.

E3: [...] e cuando se apodera el malo gime el pueblo.

$F:[\ldots]$ y en podestar malo gemirá pueblo.

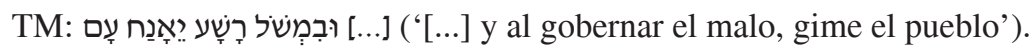

E3 $\rightarrow \beta$ : «Cuando... cuando...» $>$ «Con... con...», «crescen los» $>$ «los muchos», «se apodera» $>$ «el apoderamiento/enpoderamiento ${ }^{103} »$, «gime» > «entristeze».

\footnotetext{
${ }^{101}$ Para el proverbio completo, $c f$. CANT-IGL: «Cuando abundan los justos alégrase el pueblo, | mas cuando dominan los malvados el pueblo gime».

${ }^{102}$ enpoderamiento $\mathrm{M}$ : apoderamiento $\mathrm{MH}$.

${ }^{103}$ Ambas opciones son equipolentes: «apoderamiento» se documenta ya en el Libro de las animalias que caçan traducido ca. 1250, mucho antes que el cuatrocentista «enpoderar/ enpoderamiento», pero está ausente del corpus bíblico castellano conservado. En este abundan los casos de «apoderar», con hasta trece coincidencias de uso entre E3 y E7/E5 [Ev]. En cambio, «enpoderar» es de empleo esporádico; ausente de E3, aparece en trece ocasiones en E7/E5 [Ev], y mínimamente en E4, Alba y Oxford, con apenas coincidencias de uso entre unas y otras. Pero solo se emplea «enpoderamiento» en Dn 4:19 de Ev (y de E7/E5 si suponemos «poderamiento» como error de copia).
} 
$\beta \rightarrow$ E7/E5 [Ev]: «apoderamiento ${ }^{104} /$ enpoderamiento» $>$ «señorío».- $\beta$ $\rightarrow M$ : no cambia.

\section{4. (MH 156) Pr 29:3[a].}

IIEl varón que ama el ${ }^{105}$ saber alegra a su padre ${ }^{106}$. ( / I I Conclusión ${ }^{107}$. ( •

E7/E5 [Ev]: El varón que ama la sciencia [Ev ciencia] alegra a su padre, \{e el que usa fornicio $[\mathrm{Ev}-\mathrm{s}]$ pierde el averío $\}$.

E3: El ome que ama la ciencia alegrará a su padre, \{e el que govierna las putas estruirá averío\}.

Ferr.: Varón amán sabiduría fará alegrar su padre, \{y governán erradas perderá aver\}.

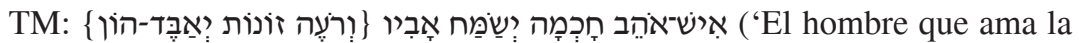
sabiduría alegra a su padre'; [...]).

Nuevo proverbio trunco. $M$ elimina la segunda parte, prescindiendo de nuevo de la organización bimembre y antitética del original. El recorte puede deberse al carácter excesivamente referencial de la parte eliminada, alejada del tono sapiencial típico, más orientado a formular principios de moral positiva o negativa que a advertir al lector sobre las consecuencias de acciones concretas de tipo pecaminoso.

$\mathrm{E} 3 \rightarrow \beta$ : «ome» > «varón», «alegrará» > «alegra».

$\beta \rightarrow$ E7/E5 [Ev]: no cambian. $\beta \rightarrow M$ : «ciencia» > «saber», forma común y menos técnica de expresar TM חָדָ / hojmá ('sabiduría'); es término que abunda en la primera parte de Palabras breves, pero no parece que su uso en la sentencia se deba a una intervención del compilador.

\footnotetext{
${ }^{104}$ En este caso, $\beta \rightarrow$ M cambiaría: «apoderamiento > «enpoderamiento». La selección por E7/E5 [Ev] del más común y tradicional «señorío»-documentado desde 1198coincide con Alba: «pero cuando ha dominación (señorío) el malo son coitados el pueblo e gimen».

${ }^{105}$ ama el M: amare $\mathrm{MH}$.

${ }^{106}$ Para el proverbio completo, $c f$. CANT-IGL: El hombre que ama la sabiduría alegra a su padre, | y quien frecuenta las rameras disipa la fortuna.

${ }^{107}$ a su padre $(\cdot /$ Conclusión M: a su padre con ilusión $\mathrm{MH}$. Así lo transcribe también al dar el explicit en su descripción de la obra (p. 39).
} 
M om. Pr 29:3[b]-Pr 31:31 (final de Pr).

$\&$ La indicación, explícita y centrada en la línea de escritura, de la «Conclusión» es señal de que la selección de proverbios por parte del compilador de Palabras breves no iba más allá de Pr 29:3[a]. De hecho, si hasta el final del capítulo (Pr 29:27) podría haber encontrado material que prolongaba el tono general, en formas y temas, de todo lo anterior ${ }^{108}$, los capítulos finales del libro, Pr 30 («Palabras de Agur») y 31 («Palabras de Lemuel»), contienen proverbios de un tipo muy distinto -por su longitud y por su organización sintáctica y retórica más compleja-, poco adecuados, en consecuencia, al carácter de su compilación.

Recibido: 20/10/2017

Aceptado: 07/12/2017

\footnotetext{
${ }^{108} C f$., por ej., en E7/E5, Pr 29:6: «En el pecado el mal omne entropieça, e el justo cata e alégrasse». Abundan también, sin embargo, el paralelismo antitético y los términos de comparación muy concretos, a los que el compilador no parece especialmente inclinado.
} 